NBER WORKING PAPER SERIES

\title{
AMBIGUITY AVERSION AND HOUSEHOLD PORTFOLIO CHOICE: EMPIRICAL EVIDENCE
}

\author{
Stephen G. Dimmock \\ Roy Kouwenberg \\ Olivia S. Mitchell \\ Kim Peijnenburg \\ Working Paper 18743 \\ http://www.nber.org/papers/w18743
NATIONAL BUREAU OF ECONOMIC RESEARCH
1050 Massachusetts Avenue
Cambridge, MA 02138
January 2013

This paper is part of the NBER's Research Program on the Economics of Aging and the Working Group on Household Portfolios. The authors gratefully acknowledge support from Netspar, the National Institute on Aging, P30 AG-012836-18, the Pension Research Council/Boettner Center for Pensions and Retirement Security, and National Institutes of Health-National Institute of Child Health and Development Population Research Infrastructure Program R24 HD-044964-9, all at the University of Pennsylvania, and the ALP teams at RAND and the University of Southern California, as well as the Wharton Behavioral Labs. We thank Jawad Addoum, Sahil Bajaj, Laurent Calvet, Nicola Gennaioli, Luigi Guiso, Debrah Meloso, Nicola Pavoni, Arno Riedl, Stefan Trautmann, Martijn van den Assem, Peter Wakker, and participants at the American Economic Association, European Economic Association, European Finance Association, European Household Finance, Financial Intermediation Research Society, Mitsui Finance Symposium, Netspar Workshop, SFS Cavalcade, and Western Finance Association conferences for helpful comments, and Tania Gutsche, Arie Kapteyn, Bart Orriens, and Bas Weerman for assistance with the survey. Yong Yu provided outstanding programming assistance. The content is solely the responsibility of the authors and does not necessarily represent the official views of the National Institute of Aging, the National Institutes of Health, the National Bureau of Economic Research or of the other institutions providing funding for this study or with which the authors are affiliated.

At least one co-author has disclosed a financial relationship of potential relevance for this research. Further information is available online at http:/www.nber.org/papers/w18743.ack

NBER working papers are circulated for discussion and comment purposes. They have not been peerreviewed or been subject to the review by the NBER Board of Directors that accompanies official NBER publications.

(C) 2013 by Stephen G. Dimmock, Roy Kouwenberg, Olivia S. Mitchell, and Kim Peijnenburg. All rights reserved. Short sections of text, not to exceed two paragraphs, may be quoted without explicit permission provided that full credit, including (C) notice, is given to the source. 
Ambiguity Aversion and Household Portfolio Choice: Empirical Evidence

Stephen G. Dimmock, Roy Kouwenberg, Olivia S. Mitchell, and Kim Peijnenburg

NBER Working Paper No. 18743

January 2013, Revised June 2014

JEL No. C83,D14,D81,G11

\section{$\underline{\text { ABSTRACT }}$}

We test the relation between ambiguity aversion and five household portfolio choice puzzles: nonparticipation, low allocations to equity, home-bias, own-company stock ownership, and portfolio underdiversification. In a representative U.S. household survey, we measure ambiguity aversion using customdesigned questions based on Ellsberg urns. As theory predicts, ambiguity aversion is negatively associated with stock market participation, the fraction of financial assets in stocks, and foreign stock ownership, but positively related to own-company stock ownership. Conditional on stock ownership, ambiguity aversion is related to portfolio under-diversification, and during the financial crisis, ambiguity-averse respondents were more likely to sell stocks.

Stephen G. Dimmock

Division of Finance and Banking

Nanyang Technological University

Singapore, 639798

dimmock@ntu.edu.sg

Roy Kouwenberg

College of Management

Mahidol University

69 Vipawadee Rangsit Rd

Bangkok, 10400, Thailand

and Erasmus University Rotterdam

cmroy@mahidol.ac.th
Olivia S. Mitchell

University of Pennsylvania

Wharton School

3620 Locust Walk, St 3000 SH-DH

Philadelphia, PA 19104-6302

and NBER

mitchelo@wharton.upenn.edu

Kim Peijnenburg

Bocconi University

Via Roentgen 1

20135 Milan

Italy

kim.peijnenburg@unibocconi.it 


\section{Introduction}

People must consider both the risk and the ambiguity of future outcomes when making financial decisions. Risk refers to events for which the probabilities of the future outcomes are known; ambiguity refers to events for which the probabilities of the future outcomes are unknown. Ellsberg (1961) argues that most people are ambiguity averse, that is, they prefer a lottery with known probabilities to a similar lottery with unknown probabilities, and numerous theoretical studies explore the implications of ambiguity for economic behavior. In particular, a large body of theory suggests that ambiguity aversion can explain several household portfolio choice puzzles. Empirical tests for some of these theoretical explanations, however, derive mainly from laboratory experiments rather than actual portfolio choices; in other cases, the proposed theoretical explanations have not previously been empirically tested.

In this paper, we provide non-laboratory empirical evidence that ambiguity aversion relates to five household portfolio choice puzzles: non-participation in equity markets, low portfolio fractions allocated to equity, home-bias, own-company stock ownership, and portfolio under-diversification. Specifically, in a nationally-representative sample of U.S. households, we use real rewards to elicit measures of individuals' ambiguity aversion and then demonstrate that these measures can explain actual portfolio choices. As theory predicts, ambiguity aversion is negatively associated with stock market participation, the fraction of financial assets allocated to stocks, and foreign stock ownership, but ambiguity aversion is positively related to owncompany stock ownership. Conditional on stock ownership, ambiguity aversion also helps to explain portfolio under-diversification.

We develop an internet survey module designed to elicit ambiguity aversion and fielded it on more than 3,000 respondents in the American Life Panel (ALP). Following the classic 
Ellsberg urn problem, the module asks respondents to choose between a lottery with known probabilities (the drawing of a ball from a box with 100 colored balls in known proportions), versus a lottery with unknown probabilities. We vary the proportions of colored balls in the lottery with known probabilities, so as to measure individual respondents' ambiguity aversion. All respondents were eligible to win real monetary incentives (a total of $\$ 23,850$ was paid to 1,590 of the respondents), as previous studies show that rewards are crucial for eliciting meaningful responses to questions involving economic preferences. Our results confirm prior laboratory studies finding substantial heterogeneity in ambiguity aversion: a substantial fraction of our respondents is ambiguity averse (52\%), a small fraction ambiguity neutral (10\%), and the remainder ambiguity seeking (38\%). Having elicited ambiguity aversion, we then test whether it can help explain household portfolio choice puzzles.

A large proportion of the U.S. population does not participate in the stock market, which is puzzling given that theoretical models using standard expected utility functions predict that all individuals will do so (Merton, 1969). For those who do participate, theory predicts they will allocate a counterfactually high fraction of assets to equity (Heaton and Lucas, 1997). Several theoretical papers suggest that ambiguity aversion can explain these puzzles, based on the assumption that investors view stock returns as ambiguous. Bossaerts, Ghirardato, Guarnaschelli, and Zame (2010), Cao, Wang, and Zhang (2005), Dow and Werlang (1992), Easley and O’Hara (2009), and Epstein and Schneider (2010), ${ }^{1}$ among others, show that ambiguity aversion can cause non-participation. Garlappi, Uppal, and Wang (2007) and

\footnotetext{
${ }^{1}$ These papers model ambiguity aversion using the multiple prior model of Gilboa (1987), Gilboa and Schmeidler (1989), and Schmeidler (1987). Bossaerts, Ghirardato, Guarnaschelli, and Zame (2010) use an extension of the multiple prior model, the $\alpha$-MaxMin model of Ghirardato, Maccheroni, and Marinacci (2004), which distinguishes between preferences towards ambiguity and beliefs about the level of ambiguity. In this paper, we do not take a stand on the "correct" underlying model of ambiguity, and our measure of ambiguity aversion is valid under all commonly-used models.
} 
Peijnenburg (2014) show that ambiguity aversion can reduce the fraction of financial assets allocated to equity.

We test the predictions of these theoretical models and find that ambiguity aversion has a significant negative relation with both stock market participation and portfolio allocations to equity. Results indicate that a one standard deviation increase in ambiguity aversion implies an 8.6\% decrease in the probability of stock market participation and a 7.1\% decrease in the fraction of financial assets allocated to equity. The results are robust to controlling for numerous variables that previous studies suggest might affect household portfolio choice, including wealth, income, age, education, risk aversion, trust, and financial literacy, among others. The module also includes two check questions to assess whether a respondent's choices are consistent; we find stronger results for respondents whose choices are consistent.

In addition to explaining participation in and allocations to equities as a broad asset class, theory suggests that ambiguity aversion can help explain portfolio puzzles related to particular categories of equity: specifically, the home-bias and own-company stock puzzles. The homebias puzzle refers to the fact that households heavily overweight domestic equity relative to mean-variance benchmarks (French and Poterba, 1991). The own-company stock puzzle refers to the fact that households voluntarily hold significant amounts of their employers' stock (Benartzi, 2001; Meulbrook, 2005; Mitchell and Utkus, 2003). Several theoretical papers argue that ambiguity aversion can explain these puzzles, because, relative to the domestic stock market, foreign stocks are relatively ambiguous and own-company stock is relatively unambiguous (e.g., Boyle, Uppal, and Wang, 2003; Boyle, Garlappi, Uppal, and Wang, 2012; Cao, Han, Hirshleifer, and Zhang, 2011; Epstein and Miao, 2003; Uppal and Wang, 2003). Thus the portfolio of an 
ambiguity-averse investor is biased away from foreign stocks but toward own-company stock. To our knowledge, we are the first to empirically test these predictions.

We find evidence consistent with both predictions. Ambiguity aversion is negatively related to foreign stock ownership, but positively related to own-company stock ownership. This pattern holds both in the overall sample, and within the subset of equity holders. The results for equity owners are of particular interest, as they demonstrate that ambiguity aversion helps to explain the composition of equity portfolios, and not only the participation decision. Our results also provide evidence that ambiguity aversion is not simply a proxy for risk aversion, since, for foreign and own-company stock ownership, the theoretical effect of risk aversion is exactly opposite to that of ambiguity aversion.

The paper also tests Heath and Tversky’s (1991) competence hypothesis, which predicts that the effect of ambiguity aversion depends on individuals' domain-specific knowledge. Although people are generally ambiguity averse towards tasks for which they do not feel competent (e.g., guessing the composition of an Ellsberg urn), people are much less ambiguity averse towards tasks for which they believe they have expertise. Hence, we expect that higher stock market competence will moderate the relation between a respondent's ambiguity aversion towards Ellsberg urns and his ambiguity aversion towards stock investments. We measure stock market competence in two ways: self-assessed stock market knowledge and financial literacy. For both measures, we find that the negative effect of ambiguity aversion on stock market participation is stronger for people with lower stock market competence, consistent with the implications of the competence hypothesis.

Furthermore, theory suggests that ambiguity aversion relates to portfolio underdiversification, with the effect of ambiguity aversion depending on the relative ambiguity of the 
overall market compared to individual stocks. Boyle, Garlappi, Uppal, and Wang (2012) find that an individual who views the overall stock market as highly ambiguous, relative to some limited number of familiar individual stocks, will invest in the individual stocks, thereby holding an under-diversified portfolio. Consistent with this hypothesis, we find that, conditional on participation, the fraction of the portfolio allocated to individual stocks is increasing in ambiguity aversion for individuals with low self-assessed knowledge about the overall stock market. These individuals view the overall stock market as highly ambiguous, and thus conditional on participation, hold only a few individual stocks.

In most models of ambiguity, the effect of ambiguity aversion is stronger when the perceived level of ambiguity is high. We therefore also test how equity owners reacted to the recent financial crisis, a period when the perceived ambiguity of future asset returns increased sharply (e.g., Bernanke, 2010; Caballero and Simsek, 2012). Our results show that respondents with higher ambiguity aversion were significantly more likely to actively sell equities during the crisis. To our knowledge, this is the first empirical test examining how ambiguity aversion affects active changes in household portfolios during times of market turmoil.

This paper contributes to the literature by testing the theoretical models that use ambiguity aversion to explain household portfolio choice. Aside from a few laboratory experiments (e.g., Bossaerts, Ghirardato, Guarnaschelli, and Zame, 2010), we are the first to show a significant relation between ambiguity aversion and stock-market participation. ${ }^{2}$ Dimmock, Kouwenberg, and Wakker (2014) develop and apply a method for eliciting ambiguity attitudes in a Dutch household survey. Although their primary focus is on developing the

\footnotetext{
2 Although not their main focus, Guiso, Sapienza, and Zingales (2008) include a control variable for ambiguity aversion, measured using a hypothetical compound lottery with known probabilities, but they do not find significant results.
} 
elicitation method, they also examine whether ambiguity aversion is related to stock market participation. In their relatively small data set, they do not find a significant relation except for a subset of respondents having low perceived knowledge about future asset returns. Because it is not their main focus, and because their data set does not contain the necessary variables, they do not test any other hypotheses related to household portfolio choice. Further, their measures of ambiguity attitudes are based on a particular model of ambiguity, the source method of Abdellaoui, Baillon, Placido, and Wakker (2011) and Chew and Sagi (2008), which differs from the models of ambiguity used in the finance literature; thus their tests do not align with the theoretical predictions in the literature. In contrast, in this paper, our measure of ambiguity aversion is consistent with the underlying models of preferences used in the finance literature.

Our data set contains detailed information about household portfolios, allowing us to test a rich set of hypotheses. Specifically, our paper is the first non-laboratory test to show that ambiguity aversion can help explain five household choice puzzles: equity non-participation, the low fraction of assets allocated to equities, home-bias, own-company stock investment, and portfolio under-diversification. We are also the first to show that ambiguity aversion relates to active portfolio changes in response to the financial crisis. Our results are consistent with the predictions of a large number of theoretical models, and we show that ambiguity aversion can help explain numerous puzzling features of households' portfolio choices.

\section{Measuring ambiguity aversion}

We developed a series of questions to elicit ambiguity aversion and implemented these questions using a special module in the ALP internet survey. Our questions are posed as choices 
between an ambiguous Box U (Unknown) ${ }^{3}$ and an unambiguous Box K (Known), similar to the famous Ellsberg (1961) two urn experiment. ${ }^{4}$ As shown in Figure 1, both boxes contain exactly 100 balls, which can be purple or orange. The respondent selects one of the boxes, and then a ball is randomly drawn from that box; he wins $\$ 15$ if that ball is purple and $\$ 0$ if the ball is orange. For Box K, the number of purple balls is explicitly stated (50 purple balls), as well as the number of orange balls (50). For Box $U$, the number of purple balls is not given, and the respondent only knows it is between 0 and 100. A respondent who prefers Box K over Box $\mathrm{U}$ is ambiguity averse; that is, he prefers known probabilities to unknown probabilities. In the survey, a respondent can also choose "Indifferent” instead of Box K or Box U. A choice of "Indifferent" implies that the respondent considers Box $\mathrm{K}$ and Box $\mathrm{U}$ equally attractive, and so he is ambiguity-neutral. An ambiguity-neutral subject treats the subjective probability of winning for Box $\mathrm{U}$ as if it were equal to the $50 \%$ known probability of winning for Box K. For this reason, we refer to $50 \%$ as Box U's ambiguity-neutral probability of winning.

Figure 1 here

To more precisely measure respondents' ambiguity aversion, we follow an approach similar to that of Baillon and Bleichrodt (2012), Baillon, Cabantous, and Wakker (2012), and Dimmock, Kouwenberg, and Wakker (2014). Specifically, the question sequence takes the respondent through a series of choices that are conditional on prior answers and converge toward the point of indifference. ${ }^{5}$ For example, suppose a respondent displays ambiguity aversion in the first round of the question, preferring Box K over Box U (see Figure 1). We then decrease Box

\footnotetext{
${ }^{3}$ Our survey module uses "box" instead of "urn," as the word "urn” might be unfamiliar to some subjects. ${ }^{4}$ We elicit ambiguity with questions about urns, rather than stocks, to avoid biases or reverse causality.

${ }^{5}$ An alternative would be to directly elicit the known probability that makes the subject indifferent between a known and an unknown lottery (e.g., Kahn and Sarin, 1988). We use a series of discrete choices as prior studies show this produces more reliably measures of preferences (e.g., Bostic, Herrnstein, and Luce, 1990; Noussair, Robbin, and Ruffieux, 2004).
} 
K's known probability of winning to $25 \%$ in the second round (see Figure A.2. in Online Appendix A). Alternatively, if the respondent chooses Box $U$ in the first round, we then increase the known probability of winning to $75 \%$. This process is repeated for up to four rounds, until the respondent's indifference point is closely approximated. ${ }^{6}$ We refer to the known probability of winning for Box $\mathrm{K}$ at which the respondent is indifferent between Box $\mathrm{K}$ and Box $\mathrm{U}$ as the matching probability (Wakker, 2010). For example, a matching probability of $40 \%$ means the respondent is indifferent between drawing a purple ball from Box K with a known probability of winning equal to 40\%, versus drawing a purple ball from Box U with an unknown probability.

A key appeal of this approach is that matching probabilities measure ambiguity aversion relative to risk aversion (because the alternative to the ambiguous choice is a risky choice, not a certain outcome). As a result, all other features of utility, such as risk aversion or probability weighting, are differenced out of the comparison. For example, different subjects might receive different utilities from a prize of $\$ 15$. But our matching probabilities measure a within-subject comparison between a risky lottery and an ambiguous lottery, and because the prize is the same for both boxes, the utility of $\$ 15$ is differenced out of the comparison. Accordingly, crosssubject differences in utility are irrelevant. Matching probabilities capture only differential preferences for ambiguity relative to risk. ${ }^{7}$

Because the ambiguity neutral probability of the ambiguous lottery is $50 \%$, a respondent with a matching probability below $50 \%$ is ambiguity averse. A respondent with a matching probability equal to $50 \%$ is ambiguity neutral, and a respondent with a matching probability above $50 \%$ is ambiguity seeking. In what follows, $q$ denotes the matching probability and we define our key measure as: Ambiguity Aversion $=50 \%-q$. Thus positive values of this measure

\footnotetext{
${ }^{6}$ Online Appendix A provides additional details about the approximation method.

${ }^{7}$ A proof is provided by Dimmock, Kouwenberg, and Wakker (2014, Theorem 5.1).
} 
indicate ambiguity aversion, zero indicates ambiguity neutrality, and negative values indicate ambiguity seeking. In some of the empirical tests we use two additional measures of ambiguity aversion. The first is simply an indicator variable equal to one if the respondent indicates ambiguity aversion for the first round of the question (i.e., if he selects Box K in the first round). ${ }^{8}$ The second is the rank transformation of the Ambiguity Aversion measure, with zero indicating the lowest level of ambiguity aversion and one the highest.

Importantly, subjects could win real rewards based on their choices, because prior studies show that this produces more reliable estimates of preferences (Smith, 1976). The instructions at the start of the survey told the subjects that one of their choices would be randomly selected and played for a chance to win $\$ 15$. We paid a total of $\$ 23,850$ in real incentives to 1,590 of the 3,258 ALP subjects. ${ }^{9}$ The RAND Corporation's ALP was responsible for determining the incentives won by respondents and making payments; accordingly, suspicion about the trustworthiness of the incentive scheme should play no role, as subjects regularly participate in ALP surveys and receive incentive payments from RAND.

In Ellsberg experiments, respondents can usually choose the winning color, to rule out potential suspicion that the ambiguous urn is manipulated to contain fewer purple balls than orange balls. In our survey we elected not to add an option to change the winning color, as we sought to keep the survey as simple as possible for use in the general population. Further, the survey was administered by RAND Corporation's ALP, which should minimize distrust. Prior studies have also demonstrated overwhelmingly that subjects are indifferent between betting on

\footnotetext{
${ }^{8}$ In theory, respondents could strategically increase the probability of winning $\$ 15$ by choosing Box $U$ in the first round, thereby increasing Box K's known probability of winning in the subsequent rounds. The indicator variable is not subject to concerns about strategic answering as it depends only on the response in the first round, before the respondent could know that there are multiple linked rounds. Further, there are a maximum of four rounds, which limits the respondents' ability to learn strategic behavior.

${ }^{9}$ Before including our survey module in the ALP panel, we piloted our questions in a laboratory experiment at the Wharton Behavioral Lab. Results of the lab experiment are available on request.
} 
either color (e.g., Abdellaoui, Baillon, Placido, and Wakker 2011; Fox and Tversky, 1998). To confirm this, we gave a separate group of 250 respondents the option to select the winning color and found no significant differences in ambiguity aversion from the main survey sample. ${ }^{10}$

Since elicited preferences likely contain measurement error, ${ }^{11}$ we also included two check questions to test the consistency of subjects' choices. After each subject completed the ambiguity questions, we estimated his matching probability: q. We then generated two check questions by changing the known probability of winning for Box $\mathrm{K}$ to $q+10 \%$ in the first question, and $q-10 \%$ in the second. Box $U$ remains unchanged. A subject's response is deemed inconsistent if he prefers the ambiguous Box $U$ in the first check question or the unambiguous Box $\mathrm{K}$ in the second check question. (Online Appendix A details the elicitation procedure including the consistency checks.)

\section{Data and variables}

Our survey module to measure ambiguity aversion was implemented in the RAND American Life Panel. ${ }^{12}$ The ALP consists of several thousand households that regularly answer Internet surveys. Households lacking Internet access at the recruiting stage are provided with a laptop and wireless service to limit selection biases. ${ }^{13}$ To further ensure the sample is representative of the U.S. population, the ALP provides survey weights used for all statistics

\footnotetext{
${ }^{10}$ In August 2013 we fielded an additional survey with 500 respondents. In this survey, half of the respondents could choose the winning color (purple or orange), while the other half could not (all other aspects of this survey were identical to the original survey, including real incentives). The mean matching probabilities of the 'color choice' and 'no color choice' groups are 0.479 and 0.459 , respectively, and the difference is not statistically significant $(p$-value $=0.31)$. Furthermore, the average matching probability of the 'color choice' group is not significantly different from that in the main survey sample.

${ }^{11}$ See Harless and Camerer (1994) and Hey and Orme (1994) for further discussion of measurement error in preference elicitation.

${ }^{12}$ See Online Appendix B for more information about the ALP.

13 See https://mmicdata.rand.org/alp/index.php?page=comparison for a comparison of the ALP to alternative data sources.
} 
reported in this paper. In addition to the ambiguity aversion variables derived from our module, we use additional variables from the ALP surveys. Table 1 defines these variables and Table 2 provides summary statistics; the last column of Table 2 also indicates the number of valid responses for each variable.

The first seven variables in Table 2 summarize our dependent variables. These financial variables were measured in different ALP survey modules, many of which included only a subset of the ALP participants. Accordingly, the sample sizes of the dependent variables differ depending on the number of people surveyed in the specific modules. We do not find any significant correlations between ambiguity aversion and inclusion in these modules, suggesting that sample selection biases are unlikely.

Stock Ownership is an indicator variable equal to one if the respondent holds stocks (either individual stocks or equity mutual funds) in his personal portfolio. The participation rate in our sample is $23 \% .^{14}$ The second row shows that the unconditional average fraction of financial assets allocated to stocks is $12 \%$; conditional on stock market participation, the average fraction is $51 \%$. For the subsequent dependent variables, the sample sizes are lower because our survey module does not perfectly overlap with the modules that collected these variables. Foreign Stock Ownership is an indicator variable equal to one if the respondent owns foreign stocks or equity mutual funds; $13 \%$ of the sample owns foreign stocks. Own-Company Stock ownership is an indicator variable equal to one if the respondent owns shares in his current or previous employer (outside of his retirement account); $5 \%$ of the sample has own-company stock ownership. For own-company stock, we restrict the sample to respondents that are employed.

\footnotetext{
${ }^{14}$ Our sample has a lower equity participation rate than that reported in some other studies, because we exclude equity ownership in 401(k) plans. Such equity holdings might not reflect active choices by the respondent, as a result of the U.S. Department of Labor's introduction of target date funds as an investment default; in this case, employees can hold equities by default, rather than due to active choice. For more on 401(k) plan investment options, see Mitchell and Utkus (2012).
} 
Individual Stock Ownership is an indicator variable equal to one if the respondent owns individual shares (not including own-company stock); $17 \%$ of the sample owns individual shares. Conditional on non-zero equity ownership, the average fraction allocated to individual stocks is $42 \%$. For a subsample of the individual stock owners, we can observe the number of individual shares that they own. Consistent with other studies of household portfolios, we find that, conditional on owning individual stocks, the median number of individual stocks held is two, which suggests that individual stock ownership is a reasonable proxy for underdiversification. The variable "Stock Sales During the Financial Crisis" is derived from a survey fielded in May 2009, ${ }^{15}$ and it is equal to one if the respondent actively sold stocks during the financial crisis, conditional on owning stocks before the crisis.

\section{Tables 1 and 2 here}

In all empirical tests we control for demographic and economic characteristics, including age, gender, ethnicity, marital status, number of children, self-reported health status, education, employment status, family income and wealth, and retirement plan type ${ }^{16}$ Controlling for these variables partials out the potential confounding effects that they might have on household portfolio choice, thus providing cleaner estimates of the effect of ambiguity aversion.

Our ALP survey module also included additional questions to measure trust, financial literacy, and risk aversion. (Online Appendix B provides the exact wording of these questions and additional details.) We include these variables to avoid omitted variable biases, as it is plausible that these variables affect portfolio choice and could measure something conceptually

\footnotetext{
${ }^{15}$ Although, the crisis module was completed nearly three years prior to our module, it is unlikely that investment choices made during the financial crisis would significantly affect respondents' ambiguity aversion preferences elicited in the urn domain three years later; as such, we do not believe reverse causality is a concern.

${ }^{16}$ For prior studies using these variables see, among others, Guiso, Sapienza, and Zingales (2008), Haliassos and Bertaut (1995), Rosen and Wu (2004), and Vissing-Jorgensen (2002).
} 
similar to ambiguity aversion. For example, it is possible that ambiguity aversion might be influenced by trust (i.e., people who distrust others may assume that ambiguous events are systematically biased against them). Following Guiso, Sapienza, and Zingales (2008), we use the trust question from the World Values Survey. ${ }^{17}$

We also control for financial literacy, as prior studies show it has a strong relation with financial decisions (e.g., Lusardi and Mitchell, 2007; van Rooij, Lusardi, and Alessie, 2011). To ensure that ambiguity aversion is not simply a proxy for low financial literacy, our survey module included three questions similar to those devised by Lusardi and Mitchell (2007) for the Health and Retirement Study. Our index of financial literacy is the number of correct responses to these questions. Table 2 shows that, on average, respondents answer slightly more than two of the questions correctly.

Our methodology is designed to elicit ambiguity aversion in a manner unaffected by risk aversion; nevertheless we control for risk aversion for two reasons. First, we seek to ensure that our ambiguity aversion variable captures a distinct component of preferences, separate from risk aversion. Second, ambiguity aversion and risk aversion could be correlated, in which case ambiguity attitudes might provide little incremental information about preferences. To measure risk aversion we modify Tanaka, Camerer, and Nguyen’s (2010) method. As shown in Figure 2, we ask the respondent to choose between a certain outcome and a risky outcome. Based on the response, the survey generates a new binary choice similar to the method for eliciting ambiguity aversion described previously. Table 2 shows that the average respondent is risk averse, but there is substantial variation and some people are risk seeking. The order of the risk and

\footnotetext{
${ }^{17}$ Although our question is the same as theirs, the ALP uses a different response scale: the ALP asks subjects to select a response along a six-point Likert scale, with zero indicating strong agreement with the statement that others can be trusted and five indicating strong disagreement; Guiso, Sapienza, and Zingales (2008) use a binary variable indicating either agreement or disagreement with this statement.
} 
ambiguity elicitation questions was randomized in the survey; in the regressions we include a dummy for the question order as a control.

Figure 2 here

Table 3 summarizes ambiguity aversion in the ALP sample. Panel A shows that $52 \%$ of the respondents are ambiguity averse, $10 \%$ are ambiguity neutral, and $38 \%$ are ambiguity seeking. These results are roughly consistent with the findings from a targeted survey of Italian households by Butler, Guiso, and Jappelli (2013), ${ }^{18}$ and they are within the range of results from a large number of studies summarized in Oechssler and Roomets (2013) and Trautmann and van de Kuilen (2013). Panel B summarizes the key ambiguity aversion measure. On average, respondents are ambiguity averse, but there is strong heterogeneity in ambiguity preferences. This finding is of importance for the finance literature, as Bossaerts, Ghirardato, Guarnaschelli, and Zame (2010) show that heterogeneity in investors' ambiguity aversion will result in equilibrium asset prices that cannot be replicated by a standard representative agent model with subjective expected utility. ${ }^{19}$ Panel C shows the results for the two check questions: the percent of respondents giving inconsistent answers is $30.4 \%$ for the first question and $14.0 \%$ for the second. These rates are similar to those found in laboratory studies of preferences (e.g., Harless and Camerer, 1994). In our regressions, we include a dummy variable for whether the respondent made errors on the check questions as a control. ${ }^{20}$

\footnotetext{
${ }^{18}$ Butler, Guiso, and Jappelli (2013) elicit ambiguity aversion in a survey of Italian retail bank investors. Their goal is to link decision making styles to ambiguity and risk attitudes, in contrast with our goals in the present paper.

${ }^{19}$ The heterogeneity in ambiguity aversion is equally strong (comparable to full sample results in Table 3) among sub-groups that matter most for financial markets, namely stockholders and wealthy individuals.

${ }^{20}$ Table C-1 of Online Appendix C shows the results of regressing the ambiguity aversion measure on the control variables. Naturally, these regressions do not imply causality; rather regression is a convenient tool to summarize the correlation structure of the data. We find that standard economic and demographic characteristics explain little of the variation in ambiguity aversion, and thus the effect of ambiguity aversion on economic decisions is not subsumed by commonly used control variables.
} 
Table 3 here

\section{Ambiguity aversion: Participation and the fraction of financial assets allocated to equities}

This section tests the relation between ambiguity aversion and household financial behavior, in particular stock market participation and the fraction of financial assets allocated to stocks. All models reported in this section include controls for age, age squared, gender, White, Hispanic, married, (ln) number of children (plus one), self-reported health status, education, employment status, (ln) family income, wealth, defined contribution plan and defined benefit plan participation dummies, financial literacy, trust, risk aversion, question order, errors on the check questions, missing data dummies, ${ }^{21}$ and a constant term. For all models, we report robust standard errors clustered at the household level.

\subsection{Ambiguity aversion and stock market participation}

Table 4 shows the results of probit models that test the relation between ambiguity aversion and stock market participation. The table reports marginal effects rather than coefficients. The dependent variable is an indicator variable equal to one if the respondent owns individual stocks or equity mutual funds, and zero otherwise. In column (1) the independent variable is the (rescaled) matching probability, Ambiguity Aversion (50\% - q). In column (2) the ambiguity aversion variable is Ambiguity Aversion Dummy: this is an indicator variable equal to one if the respondent's choice indicates ambiguity aversion in the first round of the question. In column (3) the independent variable is Ambiguity Aversion Rank, which is simply a rank transformation of the main Ambiguity Aversion variable (zero indicating the lowest level of ambiguity aversion and one the highest). We include this variable to show that

\footnotetext{
${ }^{21}$ Results are robust to excluding observations with missing data, rather than including these observations and using missing-data dummy variables. In the interest of brevity we do not report the coefficients for the missing data dummies (available on request).
} 
the significance of our main ambiguity aversion variable is not driven by outliers. The results are similar for all three variables; accordingly, in subsequent tables we focus primarily on the results for Ambiguity Aversion.

\section{Table 4 here}

Consistent with the predictions of theory, there is a significant negative relation between ambiguity aversion and stock market participation. Further, the economic magnitude is large. The coefficient in column (1) of Panel A implies that a one standard deviation increase in ambiguity aversion is associated with a 2.0 percentage point decrease in the probability of participating in the stock market (8.6\% relative to the baseline rate of 23\%). To put this in perspective, the implied economic magnitude of a one standard deviation change in ambiguity aversion is equivalent to a change in wealth of 0.41 standard deviations $(\$ 238,000)$.

Prior authors argue that modest participation costs can account for a sizeable fraction of non-participation (Haliassos and Bertaut, 1995; Gomes and Michaelides, 2005; VissingJorgensen, 2002). Such costs cannot, however, explain non-participation among those with moderate levels of financial assets (Andersen and Nielsen, 2011; Campbell, 2006). Thus, participation by those with at least some financial assets is of particular interest. We explore this issue in column (3) of Table 5, which shows results for the subset of respondents having financial assets of at least $\$ 500$ (as in Heaton and Lucas, 2000). In this restricted sample, both the statistical and economic significance of ambiguity aversion rise. The marginal effect in column (3) of Panel A of Table 5 implies a one standard deviation increase in ambiguity aversion is associated with a 3.3 percentage point decrease in the probability of participating in the stock market (8.8\% relative to the baseline participation rate in this subsample of 37.3\%). Table 5 here 
Overall, our results confirm the predictions of theory - higher ambiguity aversion is associated with lower stock market participation. Further, the results are stronger for households with at least moderate amounts of financial assets, a group whose non-participation is particularly difficult to explain.

\subsection{Measurement error in preference elicitation and other alternative explanations}

Although we find a significant relation between our measure of ambiguity aversion and stock market participation, it is important to establish that our key independent variable is, in fact, a valid measure of ambiguity aversion. The reliability of subjects' responses is one of the most common concerns that economists have with survey data. A large literature, beginning with Harless and Camerer (1994) and Hey and Orme (1994), shows that subjects often provide inconsistent responses to non-trivial questions about preferences. To empirically address this issue, our module included two check questions to test the consistency of respondents' choices, as the estimated ambiguity aversion of the respondents whose answers are inconsistent may contain greater measurement error. For this reason, columns (2) and (4) of Table 5 exclude respondents who gave inconsistent answers to either check question.

Among this subsample, ambiguity aversion is significantly higher: respondents who did not make errors on the check questions have ambiguity aversion measures 2.9 percentage points higher than the respondents who did make errors. ${ }^{22}$ The implied economic magnitude of the effect of ambiguity aversion on portfolio choice is also considerably larger in this subsample (i.e., for this subsample, the results are consistent with less attenuation bias due to measurement error in the independent variable). For instance, in column (2) of Panel A, the estimated marginal effect is nearly $29 \%$ larger than the corresponding marginal effect in column (1) for the

${ }^{22}$ Consistent with attenuation bias from measurement error, the ambiguity aversion variable is not significantly different from zero for those respondents who made errors on the check questions. 
full sample. Finding stronger results for this subsample, in which our measure of ambiguity aversion is more reliable, suggests two things. First, it supports our interpretation of the main results, while it is inconsistent with alternative explanations based on misunderstandings of the elicitation questions or measurement error. Second, our baseline estimates potentially understate the true economic magnitude of the relation between ambiguity aversion and household portfolio choice.

Another concern could be that low education or cognitive skill drive both ambiguity aversion and non-participation. In fact, ambiguity aversion is actually higher among the college educated, a finding that is directionally inconsistent with this alternative explanation. ${ }^{23}$ Part of our sample also answered a module measuring cognitive ability. In robustness tests, we find that including an index of cognitive ability does not alter the ambiguity aversion results. Further, the correlation between cognitive ability and ambiguity aversion is not significant. ${ }^{24}$

Similarly, it is possible that financial illiteracy could drive both non-participation and ambiguity aversion. Ex ante, this seems unlikely, as education and financial literacy explain little of the variation in ambiguity aversion (see Online Appendix C, Table C.1). But to guard against this possibility, we control for financial literacy. Consistent with prior studies, financial literacy has a highly significant positive association with stock market participation (van Rooij, Lusardi, and Alessie, 2011). Controlling for financial literacy, however, does not diminish the negative relation between ambiguity aversion and stock market participation.

Another potential concern is that ambiguity aversion might be correlated with risk aversion, in which case our ambiguity aversion variables might capture little incremental

\footnotetext{
${ }^{23}$ This is detailed in Online Appendix, Table C-1. The positive relation between ambiguity aversion and education is consistent with prior population studies, such as Butler, Guiso, and Jappelli (2013).

${ }^{24}$ The ALP data include measures of decision style, similar to those used in Butler, Guiso, and Jappelli (2013). We find that including these measures does not alter the results for ambiguity aversion.
} 
information. ${ }^{25}$ To control for this possibility, all specifications include our elicited measure of risk aversion. ${ }^{26}$ In the full sample, risk aversion is significant at the $5 \%$ level and positively related to equity market participation, but this effect dissipates in the subset of subjects having at least $\$ 500$ in financial assets. We find this odd relation is driven entirely by a small subset of respondents who report extreme risk-seeking in their responses. If we eliminate these riskseeking respondents from the analysis, the relation between risk aversion and participation is insignificantly negative. ${ }^{27}$ We note also, that our results for foreign and own-company stock ownership, discussed in Section 5, are directionally inconsistent with the possibility that our ambiguity aversion variable inadvertently measures risk aversion.

All specifications also include a control variable for trust in other people, following Guiso, Sapienza, and Zingales (2008). Trust is important, as the ambiguity aversion variable could conceivably measure subjects' distrust of the experiment: that is, subjects might believe that ambiguous situations are systematically biased against them. In our sample, the relation between trust and participation is directionally consistent with Guiso, Sapienza, and Zingales (2008). More importantly, the results for ambiguity aversion are robust to controlling for trust.

\subsection{Ambiguity aversion and the fraction of financial assets allocated to stocks}

Table 6 reports results from Tobit regressions that test the relation between ambiguity aversion and the fraction of financial assets allocated to stocks. Column (1) presents results

\footnotetext{
${ }^{25}$ Although our elicitation method is designed to measure ambiguity aversion indepent of any effect from risk aversion, it is still possible for ambiguity aversion and risk aversion to be correlated, for instance, if individuals who are highly risk averse also have very strong preferences for risk over ambiguity.

26 Puri and Robinson (2007) measure optimism based on peoples' miscalibration of their life expectancies, and argue that optimism significantly affects household portfolio choice. We do not have all of the information they use to calculate optimism, but for some of our respondents we observe whether they overestimate their probability of living past age 75 . Our results do not change when adding this variable as a control; results are available on request.

${ }^{27}$ Guiso, Sapienza, and Zingales (2008) also find an insignificant relationship between risk aversion and portfolio holdings
} 
using the full sample; column (2) presents results for the subsample of respondents with non-zero stock ownership.

Table 6 here

As predicted by theory (e.g., Garlappi, Uppal, and Wang, 2007; Peijnenburg, 2014), all of the columns show a negative relation between ambiguity aversion and the fraction of financial assets allocated to equity. ${ }^{28}$ This relation holds both in the full sample, and for the portfolio allocations of stockholders. In column (2), for an individual with non-zero ownership, the implied decrease in portfolio allocations to equity from a one standard deviation increase in ambiguity aversion is 3.6 percentage points (7.1\% relative to the conditional average allocation of 51.4\%). Overall, the results show a strong negative relation between ambiguity aversion and portfolio allocations to equity.

\section{Ambiguity aversion, home-bias, and own-company stock ownership}

The previous section focused on investments in stocks as a broad asset category. In contrast, this section tests the relation between ambiguity aversion and ownership of two specific categories of stocks: foreign and own-company stocks. For an ambiguity averse investor, the attractiveness of a particular category of stocks is partially determined by the investor's familiarity with that category. French and Poterba (1991, p. 225) suggest that the unfamiliarity of foreign stocks could explain the home-bias puzzle. Several theoretical papers formalize this idea, arguing that as ambiguity averse individuals are particularly reluctant to invest in foreign stocks, which they perceive as having greater ambiguity (e.g., Boyle, Garlappi, Uppal, and

\footnotetext{
${ }^{28}$ The estimated effects of ambiguity aversion are similar if we use Heckman-style selection models. We note, however, that these selection models are identified from the nonlinearity of the inverse Mill's ratio, as we do not have valid instruments for the first stage equation. And in the absence of valid instruments, selection models are frequently severly misspecified (c.f., Lennox, Francis, and Wang, 2012).
} 
Wang, 2012; Cao, Han, Hirshleifer, and Zhang, 2011; Epstein and Miao, 2003; Uppal and Wang, 2003). Following similar logic, theory suggests that ambiguity aversion can explain the owncompany stock puzzle, as ambiguity averse individuals prefer to invest in their employer's stock which for them has relatively low ambiguity (Boyle, Garlappi, Uppal, and Wang, 2012; Boyle, Uppal, and Wang, 2003; Cao, Han, Hirshleifer, and Zhang, 2011).

Table 7 shows the results of probit models that test the relation between ambiguity aversion and ownership of two specific categories of equity. In columns (1) and (2), the dependent variable equals one if the individual owns foreign stocks outside of his 401(k) plan. In columns (3) and (4), the dependent variable equals one if the individual owns shares of his employer's stock outside of his 401(k) plan. ${ }^{29}$ For the own-company stock ownership regressions, we limit the sample to individuals employed by someone other than themselves (i.e., the retired, self-employed, and unemployed are excluded, as own-company stock ownership is not meaningful for them). In columns (1) and (3), the sample includes all individuals for whom we have data. In columns (2) and (4), we limit the sample to individuals with non-zero stock ownership. All specifications include the same control variables as in Table 4, and the reported standard errors are clustered by household. The data for both dependent variables come from modules that do not perfectly overlap with our sample, so this table has fewer observations.

\section{Table 7 here}

Consistent with the predictions of theory, we find a significant negative relation between ambiguity aversion and foreign stock ownership, and a significant positive relation between ambiguity aversion and own-company stock ownership. For foreign stocks, the marginal effects reported in column (1), in which the sample includes both stock market participants and non-

${ }^{29}$ Although the prior literature largely focuses on own-company stock in 401(k) plans, we focus on holdings in non-retirement accounts as our data do not allow us to distinguish whether ownership within a retirement plan is voluntary or due to matching. 
participants, imply that a one standard deviation increase in ambiguity aversion is associated with a 2.6 percentage point decrease in the probability of owning foreign stocks. The results in column (2) show that the negative relation between ambiguity aversion and foreign stock ownership is not simply a result of the negative relation between ambiguity aversion and equity ownership. Even among equity market participants, higher ambiguity aversion is negatively associated with ownership of foreign stocks. Once again, the implied economic magnitude is large. A one standard deviation increase in ambiguity aversion is associated with a 6.9 percentage point decrease in the probability of foreign stock ownership.

Consistent with the predictions of theory, we also find a significant positive relation between ambiguity aversion and own-company stock ownership. The marginal effects reported in column (3), in which the sample includes both stock market participants and non-participants, imply that a one standard deviation increase in ambiguity aversion is associated with a 1.4 percentage point increase in the probability of own-company stock ownership. Although this coefficient is significant at only the $10 \%$ level, the result is intriguing as it suggests that the ambiguity averse are more likely to invest in own-company stock, even relative to the alternative of non-participation in any form of equity. Furthermore, column (4) shows that the positive relation between ambiguity aversion and own-company stock ownership is significant among the sample of stock-market participants. Once again, the implied economic magnitude is large. A one standard deviation increase in ambiguity aversion is associated with a 10.0 percentage point increase in own-company stock ownership.

Table 7 presents the first direct empirical evidence that ambiguity aversion is significantly related to both the home-bias and the own-company stock puzzles. Further, these results are inconsistent with the possibility that our measure of ambiguity aversion inadvertently 
captures risk aversion. Higher risk aversion should increase the probability of foreign stock ownership because of the diversification benefits and decrease the probability of own-company stock ownership because of portfolio diversification and the background risk associated with investing in one’s employer; for both foreign and own-company stock, the directional predictions of ambiguity aversion are exactly the opposite. More generally, the results in Table 7 pose a challenge to alternative interpretations of our ambiguity aversion measure; any alternative interpretation would have to be consistent with both a negative relation between our measure and most forms of equity, and a positive relation with own-company stock.

\section{Ambiguity aversion and stock market competence: Participation and under-diversification}

\subsection{Ambiguity aversion, stock market competence, and stock market participation}

The prior section tests the effect of ambiguity aversion on investment decisions for unfamiliar assets (foreign stocks) and familiar assets (own-company stock). In this section, we further test how the effect of ambiguity aversion differs across investors, depending on the investors' familiarity (or competence) with the overall stock market. These tests are motivated by the competence hypothesis of Heath and Tversky (1991), which predicts that most people are ambiguity averse towards decisions in areas that are unfamiliar or purely chance-based ambiguity (like an Ellsberg urn), but the effect of ambiguity aversion is reduced for decisions in areas for which the individual sees themselves as knowledgeable or competent. Hence individuals with high stock market competence would display less ambiguity aversion towards financial decisions, compared to Ellsberg urns (a low competence task). Conversely, individuals with low stock market competence would display similar ambiguity aversion towards financial decisions and towards Ellsberg urns, as they do not feel competent in either setting. This implies 
that the relation between ambiguity aversion (based on Ellsberg urns) and portfolio choice should be stronger for those with relatively low stock market competence.

In this section, we use two direct measures of low stock market competence. First, we identify respondents whose self-assessed financial knowledge is very low. ${ }^{30}$ Second, we identify respondents who made errors on the financial literacy questions. We then separately estimate the effect of ambiguity aversion within two sub-groups: those with high competence and those with low competence. We acknowledge the possibility that these measures of stock market competence could be endogenous. For example, individuals who own stocks may learn from their experience, creating a reverse causality problem. Alternatively, both stock ownership and stock market competence could be determined by some other factor (for a lucid discussion of potential endogeneity problems in studies of financial literacy, see van Rooij, Lusardi, and Alessie, 2011). The potential endogeneity problems, however, primarily affect the interpretation of the coefficients for the stock market competence variables, not the interaction of stock market competence with ambiguity aversion.

In Table 8 we test how ambiguity aversion and stock market competence interact to affect stock market participation. For ease of comparison, the first column repeats the results from Table 4, which shows the relation between ambiguity aversion and stock market participation controlling for the level of stock market competence (proxied by the number of correct responses on the financial literacy questions). In contrast, columns (2) and (3) also allow stock market competence to affect the sensitivity of the relation between ambiguity aversion and stock market participation. In these columns we estimate the effect of ambiguity aversion separately for the

\footnotetext{
${ }^{30}$ Our ALP survey includes the following question: "How would you rate your knowledge about the stock market?" with answers measured on a 5-point scale (very low, low, moderate, high, very high). We use 'very low' as a cutoff because more than $30 \%$ of respondents rate their knowledge as very low. The results are qualitatively similar if we instead use `low’ as the cutoff.
} 
low and high self-assessed stock market knowledge (or financial literacy) groups. In these specifications we also replace the financial literacy control variable with the variable used to divide the sample (i.e., in column (2) the financial literacy control variable is replaced with selfassessed stock market knowledge rather than the number of correct answers on the financial literacy questions). Aside from these changes, the regressions are identical to those in Table 4.

\section{Table 8 here}

Consistent with the Heath and Tversky (1991) competence hypothesis, Table 8 shows that the effect of ambiguity aversion is always more statistically significant in the subset of respondents reporting low stock market competence. For both measures of stock market competence, there is a stronger negative relation between ambiguity aversion and participation for individuals with lower competence. For example, the results in column (2) imply that a one standard deviation increase in ambiguity aversion is associated with a 4.6 percentage point decrease in stock market participation for an individual with low stock market competence, compared to an insignificant 1.2 percentage point decrease for an individual with high stock market competence. Note, however, that the difference in the effect of ambiguity aversion between the high and low competence groups is not statistically significantly, so we cannot conclude that the effect of ambiguity aversion is different for the low and high competence groups.

\subsection{Ambiguity aversion, stock market competence, and portfolio under-diversification}

Conditional on stock market participation, many households hold portfolios that are extremely under-diversified relative to mean-variance efficient benchmarks (Blume and Friend, 1975; Goetzmann and Kumar, 2008; Polkovnichenko, 2005). The theoretical model of Boyle, Garlappi, Uppal, and Wang (2012) suggests that ambiguity aversion can explain this puzzle. In 
their model, portfolio diversification is determined by the relative ambiguity of the overall market versus that of a few undiversified, but potentially "familiar", assets. An investor who is ambiguity averse, and who views the overall market as more ambiguous than the familiar stocks, will hold an undiversified portfolio of familiar stocks. An ambiguity averse investor who views the overall market as highly ambiguous, and does not view any individual stocks as familiar, will not participate at all. An ambiguity averse investor who does not view the overall market as highly ambiguous will hold a diversified portfolio. In this section, we test these predictions using our two measures of stock market competence (self-assessed stock market knowledge and financial literacy) as measures of the investor's perceived ambiguity of the overall stock market. We then test whether the interaction of ambiguity aversion and perceived ambiguity can help to explain the portfolio under-diversification puzzle.

Table 9 presents the results. As our goal is to examine allocations of equity owners, we limit the sample to only those who participate in the stock market. In columns (1) to (3), we report probit estimates of models in which the dependent variable is equal to one for respondents who own individual stocks, and zero otherwise. In columns (4) to (6), we report estimates from a Tobit model in which the dependent variable is the fraction of equity allocated to individual stocks. ${ }^{31}$ We include both specifications for completeness but focus our discussion on the Tobit results, as Calvet, Campbell, and Sodini $(2007,2009)$ present evidence suggesting that the proportion of equity held in individual stocks is a reasonable proxy for portfolio underdiversification. ${ }^{32}$ Furthermore, the median individual stock owner in our sample owns only two stocks, and over $86 \%$ hold fewer than eight stocks. Note that our measures of individual stock ownership do not include foreign stocks or own-company stock. Our measures of stock market

\footnotetext{
${ }^{31}$ We have fewer observations for the Tobit models as we do not observe the amount of individual stock ownership for all respondents.

${ }^{32}$ We thank Laurent Calvet for suggesting this measure to us.
} 
competence concern knowledge about stocks in general (i.e., about the overall market) but we do not have measures of whether there are certain "familiar" stocks available to the individual (and if such a measure were available, reverse causality would be a concern).

\section{Table 9 here}

Results in columns (1) and (4), in which we do not consider stock market competence, show a significant negative relation between ambiguity aversion and ownership of individual stocks. A one standard deviation increase in an individual's ambiguity aversion implies a 7.7 percentage point reduction in the probability that an equity owner holds individual stocks and implies a 9.7 percentage point lower portfolio allocation to individual stocks. The theoretical direction of the effect of ambiguity aversion is conditional on the relative perceived ambiguity of the overall market versus that of individual stocks. The negative relation that we find implies that, in aggregate, investors perceive that the returns of individual stocks have greater ambiguity than the returns of the overall market.

In columns (2) and (5), we split the sample based on self-assessed stock market knowledge, and in columns (3) and (6) we split the sample based on correct answers to the financial literacy questions. Consistent with the model of Boyle, Garlappi, Uppal, and Wang (2012), there is a negative relation between ambiguity aversion and individual stock ownership for investors who do not view the overall market as highly ambiguous. Although theory predicts a positive relation between ambiguity aversion and under-diversification for investors who view the market as highly ambiguous, in the probit regressions the relation is not significant.

The Tobit regression results in columns (5) and (6) provide the strongest evidence supporting ambiguity aversion as an explanation for under-diversification. There is a negative relation between ambiguity aversion and the fraction of equity allocated to individual stocks for 
investors with high stock market knowledge, but a positive relation for investors with low stock market knowledge. Consistent with the predictions of theory, conditional on stock market participation, people who are ambiguity averse and who view the overall market as highly ambiguous hold highly under-diversified portfolios; for this group, the results in column (5) imply that a one standard deviation increase in ambiguity aversion implies a 38.9 percentage point increase in the fraction of equity allocated to individual stocks. In contrast, those who are ambiguity averse but do not view the overall market as highly ambiguous allocate little to individual stocks; for this group, a one standard deviation increase in ambiguity aversion implies an 11.4 percentage point decrease in the fraction of equity allocated to individual stocks. ${ }^{33}$ Similar to the results for home-bias and own-company stock ownership, these results are directionally inconsistent with the possibility that our measure of ambiguity aversion inadvertently measures risk aversion: risk aversion would imply a negative relation with portfolio under-diversification, regardless of stock market competence.

For the low stock market knowledge results, the apparent inconsistency between the probit and Tobit regressions is due to the bimodal nature of individual stock ownership: in general, investors allocate either a small fraction of their total equity holdings to a few individual stocks, or they allocate all of their equity to a few individual stocks. Hence the dummy variable indicating ownership of individual stocks is not a good proxy for diversification, as it mixes well-diversified investors that hold a few individual stocks on top of mutual funds, with very undiversified investors. Investors with high ambiguity aversion and low competence tend to invest all of their equity in a few stocks (conditional on participation).

\footnotetext{
${ }^{33}$ Barberis and Huang (2008) suggest that probability weighting drives under-diversication. In a robustness test we include probability weighting as a control and the results do not change.
} 
Overall, then, the results support the argument that ambiguity aversion relates to portfolio under-diversification, but highlight the complexity of this relation, as the effect of ambiguity aversion depends on the relative ambiguity of the overall market versus individual stocks.

\section{Ambiguity aversion and investor behavior during the financial crisis}

In this section, we test how ambiguity aversion relates to investors' reactions to the financial crisis. The theoretical model of Mele and Sangiorgi (2013) shows that ambiguity aversion can cause investors to exit the stock market when the perceived level of ambiguity increases, which in turn causes large changes in prices. ${ }^{34}$ Several authors suggest that perceived ambiguity increased sharply during the financial crisis (e.g., Bernanke, 2010; Caballero and Simsek, 2013). Accordingly, we test whether, conditional on owning equities before the financial crisis, individuals with higher ambiguity aversion were more likely to actively sell equities during the financial crisis. ${ }^{35}$ These tests are conceptually different from those in the prior sections; rather than testing the cross-sectional relation between ambiguity aversion and ownership, here we test whether ambiguity aversion can explain differential responses to changes in aggregate uncertainty.

The dependent variable in Table 10 is an indicator equal to one for respondents who actively sold equities during the financial crisis. For respondents who both bought and sold equities during this period, we count only the respondents who sold more than they bought. The regressions include the same control variables as in Table 4. We report marginal effects rather than coefficients, and standard errors are clustered by household.

\footnotetext{
${ }^{34}$ See Andersen, Ghysels, and Juergens (2009) for tests of the relation between time-varying uncertainty and asset prices.

${ }^{35}$ Our tests are similar in spirit to those of Butler, Guiso, and Jappelli (2013) who show that intuitive and deliberative investors reacted differently to the financial crisis.
} 


\section{Table 10 here}

Our results support the idea that ambiguity aversion interacts with time-varying levels of economic uncertainty: respondents with higher ambiguity aversion were more likely to actively reduce their equity holdings during the financial crisis. The estimated coefficient implies that a one standard deviation increase in ambiguity aversion is associated with a 4.1 percentage point increase in the probability of selling stocks. Our results compliment the studies on time-varying uncertainty and asset prices, by showing that, following an increase in perceived uncertainty, variation in ambiguity aversion can explain cross-sectional differences in portfolio changes.

\section{Conclusion}

Using real incentives, we measure ambiguity aversion in a large representative survey of the U.S. population and test how ambiguity aversion relates to household portfolio choice. We find that most Americans are ambiguity averse, yet there is substantial variation in ambiguity preferences. The results show that ambiguity aversion can help to explain five household portfolio choice puzzles: non-participation, low fractional portfolio allocations to equities, homebias, own-company stock ownership, and portfolio under-diversification.

We find that ambiguity aversion is negatively associated with stock market participation and with the fraction of financial assets allocated to equities, consistent with a large theoretical literature. Our results are robust to controlling for many other factors that previous studies use to explain household portfolio choice. Additionally, and consistent with theory, we find that ambiguity aversion is negatively associated with foreign stock ownership, even among stock market participants, and positively associated with own-company stock ownership. Furthermore, we show that the relation between ambiguity aversion and household portfolio choice patterns is stronger for respondents with lower self-assessed stock market knowledge, consistent with the 
competence hypothesis. The interaction of ambiguity aversion and stock market knowledge helps explain the empirically-observed fact of household portfolio under-diversification. We also find that, conditional on non-zero stock ownership before the financial crisis, individuals with greater ambiguity aversion were more likely to actively sell equities during the crisis. Our findings suggest that policies designed to increase financial literacy and stock market competence could improve financial decisionmaking, in part by reducing the effect of ambiguity aversion. 


\section{References}

Abdellaoui, M., A. Baillon, L. Placido, and P.P. Wakker. 2011. The Rich Domain of Uncertainty: Source Functions and Their Experimental Implementation. American Economic Review 101, 695-723.

Anderson, E.W., E. Ghysels, and J.L. Juergens. 2009. The Impact of Risk and Uncertainty on Expected Returns. Journal of Financial Economics 94, 233-263.

Andersen, S., and K.M. Nielsen. 2011. Participation Constraints in the Stock Market: Evidence from Unexpected Inheritance Due to Sudden Death. Review of Financial Studies 24, 1667-1697.

Barberis, N., and M. Huang. 2008. Stocks as Lotteries: The Implications of Probability Weighting for Security Prices. American Economic Review 98, 2066-2100.

Baillon, A., and H. Bleichrodt. 2012. Testing Ambiguity Models through the Measurement of Probabilities for Gains and Losses. Working Paper, Erasmus University Rotterdam.

Baillon, A., L. Cabantous, and P.P. Wakker. 2012. Aggregating Imprecise or Conflicting Beliefs: An Experimental Investigation using Modern Ambiguity Theories. Journal of Risk and Uncertainty 44, 115-147.

Benartzi, S. 2001. Excessive Extrapolation and the Allocation of 401(k) Accounts to Company Stock. Journal of Finance 56, 1747-1764.

Bernanke, B.S. 2010. Implications of the Financial Crisis for Economics. Prepared remarks for the Princeton University Conference co-sponsored by the Bendheim Center for Finance and the Center for Economic Policy Studies.

www.federalreserve.gov/newsevents/speech/bernanke20100924a.pdf

Blume, M.E., and I. Friend. 1975. The Asset Structure of Individual Portfolios and Some Implications for Utility Functions. Journal of Finance 30, 585-603.

Bossaerts, P., P. Ghirardato, S. Guarnaschelli, and W. Zame. 2010. Ambiguity in Asset Markets: Theory and Experiment. Review of Financial Studies 23, 1325-1359.

Boyle, P., L. Garlappi, R. Uppal, and T. Wang. 2012. Keynes Meets Markowitz: The Trade-Off Between Familiarity and Diversification. Management Science 58, 253-272.

Boyle, P., R. Uppal, and T. Wang. 2003. Ambiguity Aversion and the Puzzle of Own-Company Stock in Pension Plans. Working Paper, University of Waterloo.

Bostic, R., R.J. Herrnstein, and R.D. Luce. 1990. The Effect on the Preference-Reversal Phenomenon of Using Choice Indifferences. Journal of Economic Behavior and Organization 13, 193-212.

Butler, J.V., L. Guiso, and T. Jappelli. 2013. The Role of Intuition and Reasoning in Driving Aversion to Risk and Ambiguity. Theory and Decision, forthcoming.

Caballero, R., and A. Simsek. 2013. Fire Sales in a Model of Complexity. Journal of Finance 68, 2549-2587.

Calvet, L., J.Y. Campbell, and P. Sodini. 2007. Down or Out: Assessing the Welfare Costs of Household Investment Mistakes. Journal of Political Economy 115, 707-747. 
Calvet, L., J.Y. Campbell, and P. Sodini. 2009. Measuring the Financial Sophistication of Households. American Economic Review 99, 393-398.

Campbell, J.Y. 2006. Household Finance. Journal of Finance 61, 1553-1604.

Cao, H.H., B. Han, D. Hirshleifer, and H.H. Zhang. 2011. Fear of the Unknown: Familiarity and Economic Decisions. Review of Finance 15, 173-206.

Cao, H.H., T. Wang, and H.H. Zhang. 2005. Model Uncertainty, Limited Market Participation, and Asset Prices. Review of Financial Studies 18, 1219-1251.

Chew, S.H., and J.S. Sagi. 2008. Small Worlds: Modeling Attitudes towards Sources of Uncertainty. Journal of Economic Theory 139, 1-24.

Dimmock, S.G., R. Kouwenberg, and P.P. Wakker. 2014. Ambiguity Attitudes in a Large Representative Sample. Working Paper, Erasmus University Rotterdam.

Dow, J., and S.R.C. Werlang. 1992. Uncertainty Aversion, Risk Aversion and the Optimal Choice of Portfolio. Econometrica 60, 197-204.

Easley, D., and M. O’Hara. 2009. Ambiguity and Nonparticipation: The Role of Regulation. Review of Financial Studies 22, 1817-1843.

Ellsberg, D. 1961. Risk, Ambiguity, and the Savage Axioms. Quarterly Journal of Economics 75, 643-669.

Epstein, L.G., and J. Miao. 2003. A Two-Person Dynamic Equilibrium Under Ambiguity. Journal of Economic Dynamics and Controls 27, 1253-1288.

Epstein, L.G., and M. Schneider. 2010. Ambiguity and Asset Markets. Annual Review of Financial Economics 2, 315-346.

Fox, C.R., and A. Tversky. 1998. A Belief Based Account of Decision under Uncertainty. Management Science 44, 879-895.

French, K.R., and J.M. Poterba. 1991. Investor Diversification and International Equity Markets. American Economic Review 81, 222-226.

Garlappi, L., R. Uppal, and T. Wang. 2007. Portfolio Selection with Parameter and Model Uncertainty: A Multi-Prior Approach. Review of Financial Studies 20, 42-81.

Ghirardato, P., F. Maccheroni, and M. Marinacci. 2004. Differentiating Ambiguity and Ambiguity Attitude. Journal of Economic Theory 118, 133-173.

Gilboa, I. 1987. Expected Utility with Purely Subjective Non-Additive Probabilities. Journal of Mathematical Economics 16, 65-88.

Gilboa, I., and D. Schmeidler. 1989. Maxmin Expected Utility with Non-Unique Priors. Journal of Mathematical Economics 18, 141-153.

Goetzmann, W.N., and A. Kumar. 2008. Equity Portfolio Diversification. Review of Finance 12, 433-463.

Gomes, F., and A. Michaelides. 2005. Optimal Life-Cycle Asset Allocation: Understanding the Empirical Evidence. Journal of Finance 60, 869-904. 
Guiso, L., P. Sapienza, and L. Zingales. 2008. Trusting the Stock Market. Journal of Finance 63, 2557-2600.

Haliassos, M., and C.C. Bertaut. 1995. Why Do So Few Hold Stocks? Economic Journal 105, 1110-1129.

Harless, D.W., and C.F. Camerer. 1994. The Predictive Utility of Generalized Expected Utility Theories. Econometrica 62, 1251-1289.

Heath, C., and A. Tversky. 1991. Preference and Belief: Ambiguity and Competence in Choice under Uncertainty. Journal of Risk and Uncertainty 4, 5-28.

Heaton, J., and D. Lucas. 1997. Market Frictions, Savings Behavior, and Portfolio Choice. Macroeconomic Dynamics 1, 76-101.

Heaton, J., and D. Lucas. 2000. Portfolio Choice and Asset Prices: The Importance of Entrepreneurial Risk. Journal of Finance 55, 1163-1198.

Hey, J.D., and C. Orme. 1994. Investigating Generalizations of Expected Utility Theory Using Experimental Data. Econometrica 62, 1291-1326.

Kahn, B.E., and R.K. Sarin. 1988. Modeling Ambiguity in Decisions under Uncertainty. Journal of Consumer Research 15, 265-272.

Lennox, C.S., J.R. Francis, and Z. Wang. 2012. Selection Models in Accounting Research. Accounting Review 87, 589-616.

Lusardi, A., and O.S. Mitchell. 2007. Baby Boomer Retirement Security: The Roles of Planning, Financial Literacy, and Housing Wealth. Journal of Monetary Economics 54, 205-224.

Mele, A., and F. Sangiorgi. 2013. Uncertainty, Information Acquisition and Price Swings in Asset Markets. Working Paper, Swiss Finance Institute.

Merton, R.C. 1969. Lifetime Portfolio Selection under Uncertainty: The Continuous-Time Case. Review of Economics and Statistics 51, 247-257.

Meulbrook, L. 2005. Company Stock in Pension Plans: How Costly Is It? Journal of Law and Economics 48, 443-474.

Mitchell, O.S., and S.P. Utkus. 2003. The Role of Company Stock in Defined Contribution Plans. In The Pension Challenge: Risk Transfers and Retirement Income Security. Eds. Olivia S. Mitchell and Kent Smetters. Oxford, UK: Oxford University Press: 33-70.

Mitchell, Olivia S. and S. P. Utkus. 2012. Target-Date Funds and Portfolio Selection in 401(k) Plans. NBER Working Paper 17911.

Noussair, C., S. Robbin, and B. Ruffieux. 2004. Revealing Consumers’ Willingness-to-Pay: A Comparison of the BDM Mechanism and the Vickrey Auction. Journal of Economic Psychology 25, 725-741.

Oechssler, J., and A. Roomets. 2013. A Test of Mechanical Ambiguity. Working Paper, University of Heidelberg.

Peijnenburg, K. 2014. Life-Cycle Asset Allocation with Ambiguity Aversion and Learning. Working Paper, Bocconi University. 
Polkovnichenko, V. 2005. Household Portfolio Diversification: A Case for Rank-Dependent Preferences. Review of Financial Studies 18, 1467-1502.

Puri, M., and D.T. Robinson. 2007. Optimism and Economic Choice. Journal of Financial Economics 86, 71-99.

van Rooij, M., A. Lusardi, and R. Alessie. 2011. Financial Literacy and Stock Market Participation. Journal of Financial Economics 101, 449-472.

Rosen, H.S., and S. Wu. 2004. Portfolio Choice and Health Status. Journal of Financial Economics 72, 457-484.

Schmeidler, D. 1989. Subjective Probability and Expected Utility without Additivity. Econometrica 57, 571-587.

Smith, V.L. 1976. Experimental Economics: Induced Value Theory. American Economic Review 66, 274-279.

Tanaka, T., C.F. Camerer, and Q. Nguyen. 2010. Risk and Time Preferences: Linking Experimental and Household Survey Data from Vietnam. American Economic Review 100, 557-571.

Trautmann, S.T., and G. van de Kuilen. 2013. Ambiguity Attitudes. In Keren, G., and Wu, G. (Ed.), Handbook of Judgment and Decision Making. Oxford, United Kingdom, forthcoming.

Uppal, R., and T. Wang. 2003. Model Misspecification and Underdiversification. Journal of Finance 58, 2465-2486.

Vissing-Jorgensen, A. 2002. Towards an Explanation of Household Portfolio Choice Heterogeneity: Nonfinancial Income and Participation Cost Structures. NBER Working Paper 8884.

Wakker, P.P. 2010. Prospect Theory for Risk and Ambiguity. Cambridge University Press, Cambridge, United Kingdom. 
Figure 1. Choosing between two boxes with purple and orange balls, one having a known (50\%) chance of winning and the other ambiguous

This figure shows a screen shot from our ALP module representing the first question in the ambiguity elicitation sequence. Box $\mathrm{K}$ has a $50 \%$ initial known probability of winning; Box $\mathrm{U}$ has an unknown mix of purple and orange balls. If the respondent selects "Box K", he is taken to a new question with a lower probability of winning in Box K (fewer purple balls), while if he selects "Box $U$ " the next question has a higher winning probability of winning in Box K (more purple balls). If the respondent selects "Indifferent," or after four rounds, the question sequence is complete.

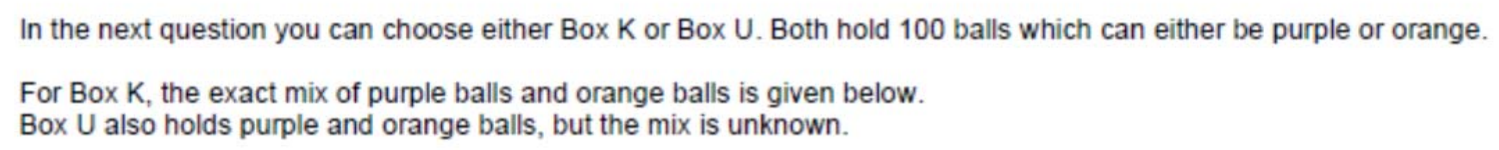

One ball will be drawn at random from the box you choose. You will win $\$ 15$ if a purple ball is drawn.

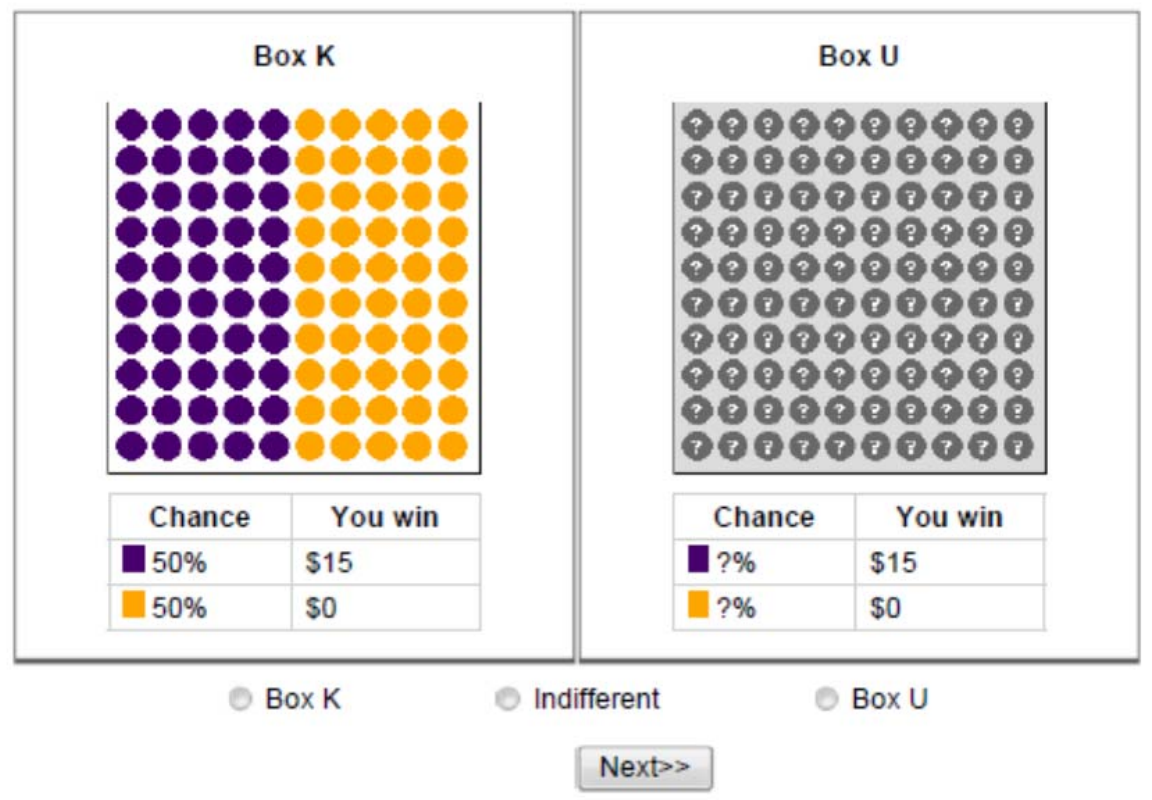


Figure 2. Choosing between two Boxes with purple and orange balls, one having a sure $(\mathbf{1 0 0 \% )}$ chance of winning and the other having a risky but well-defined probability distribution of outcomes

This Figure shows a screen shot from our ALP module in the probability risk sequence. If the respondent chooses Box A, he wins with certainty; if he chooses Box B, winning is random. If he selects "Box A" the respondent gets a new question with a higher probability of winning in Box B (more purple balls), while if he selects "Box B" the next question has a lower winning probability in Box B. If he selects "Indifferent," the question sequence is complete.
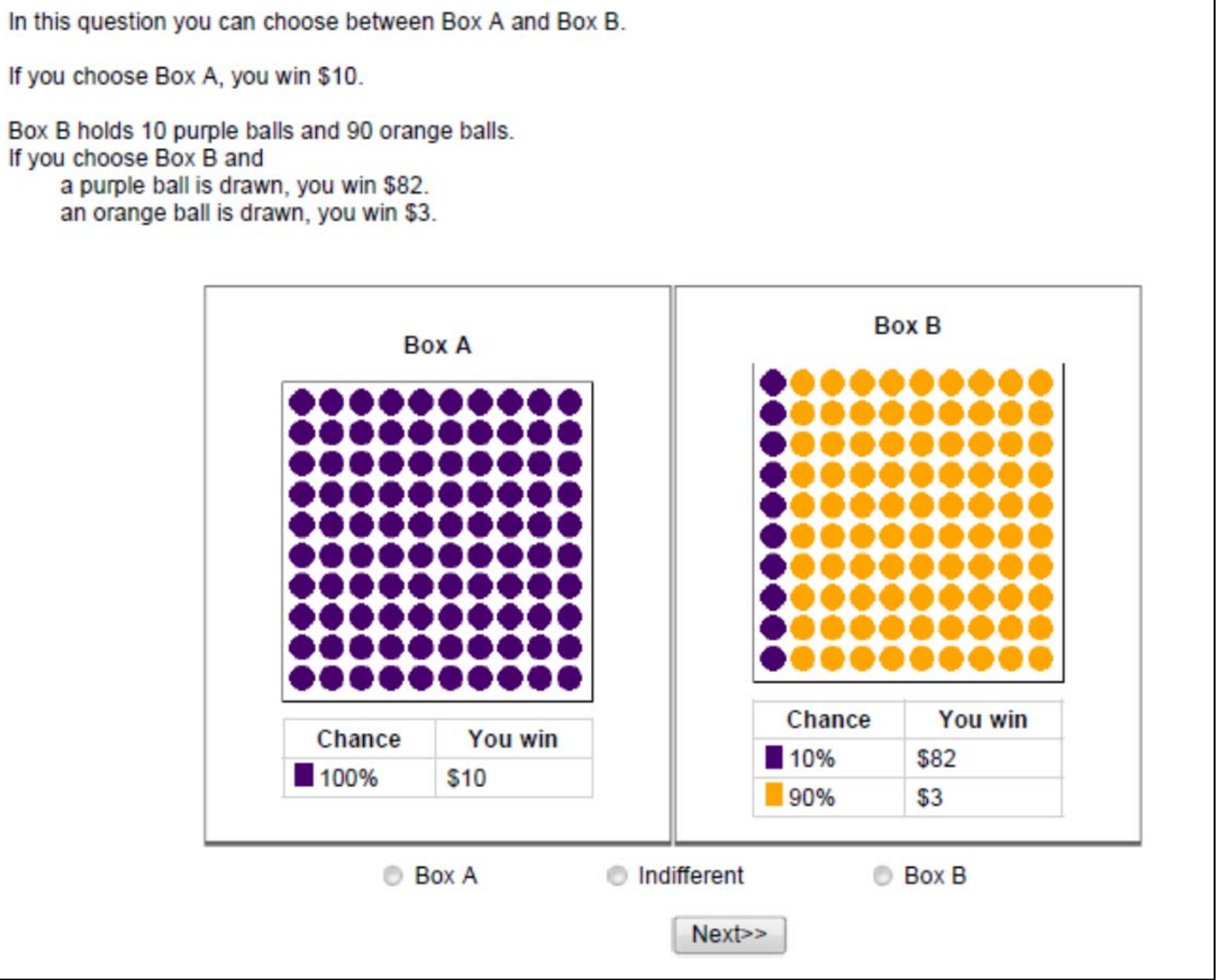
Table 1. Variable definitions

\begin{tabular}{|c|c|}
\hline Stock Ownership & $\begin{array}{l}\text { Indicator that respondent holds equities in his personal portfolio } \\
\text { (stocks or stock mutual funds) }\end{array}$ \\
\hline Fraction Allocated to Stocks & $\begin{array}{l}\text { Equity holdings as a \% of financial assets } \\
\text { (checking, saving, money market, bonds, CDs, mutual funds, and stocks) }\end{array}$ \\
\hline Foreign Stock Ownership & Indicator that respondent holds foreign stocks in his personal portfolio \\
\hline $\begin{array}{l}\text { Own-Company Stock } \\
\text { Ownership }\end{array}$ & Indicator that respondent holds his employer's stocks in his personal portfolio \\
\hline Individual Stock Ownership & Indicator that respondent holds individual stocks in his personal portfolio \\
\hline $\begin{array}{l}\text { Fraction of Equity Allocated to } \\
\text { Individual Stocks }\end{array}$ & Individual stock holdings as a \% of assets invested in stocks \\
\hline Stock Sales during Crisis & Indicator if respondent actively sold stocks during financial crisis \\
\hline Age & Age in years \\
\hline Male & Indicator for male \\
\hline White & Indicator if respondent considers himself primarily White \\
\hline Hispanic & Indicator if respondent considers himself primarily Hispanic \\
\hline Married & Indicator if respondent is married or has a partner \\
\hline Number of Children & Number of living children \\
\hline Health & $\begin{array}{l}\text { Self-reported health status ranging from 0-4; } 0 \text { indicates "Poor" and } 4 \\
\text { indicates "Excellent" }\end{array}$ \\
\hline LT High School & Indicator if respondent did not complete high school \\
\hline High School Graduate & Indicator if respondent completed high school but not college \\
\hline College+ & Indicator if respondent completed college \\
\hline Employed & Indicator if respondent is employed \\
\hline Family Income & $\begin{array}{l}\text { Total income for all household members older than } 15 \text {, including from jobs, } \\
\text { business, farm, rental, pension benefits, dividends, interest, social security, } \\
\text { and other income }\end{array}$ \\
\hline Wealth & $\begin{array}{l}\text { The sum of net financial wealth, net housing assets, and imputed social } \\
\text { security wealth using respondent self-reported claim ages, actual or estimated } \\
\text { monthly benefits, and cohort life tables }\end{array}$ \\
\hline Defined Contribution & Indicator if respondent has a defined contribution pension plan \\
\hline Defined Benefit & Indicator if respondent has a defined benefit pension plan \\
\hline Financial Literacy & $\begin{array}{l}\text { Number of financial literacy questions answered correctly } \\
\text { (out of } 3 \text { total; see Online Appendix C) }\end{array}$ \\
\hline Trust & $\begin{array}{l}\text { Ranges from } 0 \text { to } 5 ; 0 \text { corresponds to "most people can be trusted" and } 5 \\
\text { corresponds to "you can't be too careful" }\end{array}$ \\
\hline Risk Aversion & $\begin{array}{l}\text { Estimated coefficient of risk aversion based on lottery questions, }>0 \text { if risk } \\
\text { averse, }=0 \text { if risk neutral, }<0 \text { if risk seeking }\end{array}$ \\
\hline Question Order & $\begin{array}{l}\text { Indicator if subject answered the risk aversion question before } \\
\text { the ambiguity questions (the question order was randomized) }\end{array}$ \\
\hline
\end{tabular}


Table 2. Summary statistics of outcome and control variables

This table reports summary statistics of the variables used in our study; variable definitions are provided in Table 1. The summary statistics for Fraction Allocated to Stocks are shown for all respondents and for the subsample of respondents with a non-zero allocation to equity. The last column shows the number of non-missing observations for each variable. All results use ALP survey weights and the sample omits 188 people who spent fewer than two minutes on the ambiguity questions.

\begin{tabular}{lrrrrrr}
\hline & Mean & Std. Dev. & Min & Median & Max & $N$ \\
\hline Stock Ownership (\%) & 0.23 & 0.42 & 0 & 0 & 1 & 3,025 \\
Fraction Allocated to Stocks (\%) & 0.12 & 0.27 & 0 & 0 & 1 & 3,030 \\
Foreign Stock Ownership (\%) & 0.13 & 0.34 & 0 & 0 & 1 & 799 \\
Own-Company Stock & 0.05 & 0.22 & 0 & 0 & 1 & 670 \\
Ownership (\%) & & & & & & \\
Individual Stock Ownership (\%) & 0.17 & 0.38 & 0 & 0 & 1 & 2,757 \\
Fraction Allocated to Individual & 0.42 & 0.44 & 0 & 0.24 & 1 & 321 \\
Stocks Conditional (\%) & & & & & & \\
Stock Sales during Crisis (\%) & 0.07 & 0.25 & 0 & 0 & 1 & 528 \\
Age & 46.38 & 15.20 & 18 & 48 & 70 & 3,070 \\
Male (\%) & 0.48 & 0.50 & 0 & 0 & 1 & 3,070 \\
White (\%) & 0.81 & 0.39 & 0 & 1 & 1 & 3,066 \\
Hispanic (\%) & 0.18 & 0.38 & 0 & 0 & 1 & 3,069 \\
Married (\%) & 0.64 & 0.48 & 0 & 1 & 1 & 2,695 \\
Number of Children & 1.67 & 1.62 & 0 & 2 & 13 & 3,024 \\
Health & 2.48 & 0.93 & 0 & 3 & 4 & 2,969 \\
LT High School (\%) & 0.10 & 0.29 & 0 & 0 & 1 & 3,069 \\
High School (\%) & 0.34 & 0.47 & 0 & 0 & 1 & 3,069 \\
College+ (\%) & 0.56 & 0.50 & 0 & 1 & 1 & 3,069 \\
Employed (\%) & 0.49 & 0.50 & 0 & 0 & 1 & 3,068 \\
Family Income (\$) & 317,076 & 584,485 & $-88,743$ & 112,928 & $4,188,110$ & 2,969 \\
Wealth (\$) & 0.47 & 0.50 & 0 & 0 & 1 & 2,991 \\
Defined Contribution & 0.10 & 0.31 & 0 & 0 & 1 & 2,991 \\
Defined Benefit & 2.18 & 0.93 & 0 & 2 & 3 & 3,070 \\
Financial Literacy & 3.20 & 1.41 & 0 & 3 & 5 & 3,035 \\
Trust & 0.34 & 0.45 & -0.50 & 0.41 & 0.98 & 3,036 \\
Risk Aversion & 0.50 & 0.50 & 0 & 1 & 1 & 3,070 \\
Question Order & & & & & & \\
\hline
\end{tabular}




\section{Table 3. Ambiguity aversion of the U.S. population}

This table shows ambiguity aversion in the U.S. population measured using our ALP survey module. Panel A shows the proportion of respondents who are ambiguity averse, ambiguity seeking, or ambiguity neutral, as revealed by their first-round choice between Box K and Box U (see text and Figure 1). Panel B summarizes the Ambiguity Aversion measure. We define Ambiguity Aversion $=50 \%-q ; q$ denotes the matching probability for Box U in Figure 1 (with two ball colors, in unknown proportions). Panel C summarizes the percentage of respondents who gave inconsistent answers to the two check questions.

\begin{tabular}{|c|c|c|c|c|c|}
\hline \multicolumn{6}{|c|}{ Panel A: Proportion of Respondents Ambiguity Averse, Neutral, and Seeking (\%) } \\
\hline Ambiguity Averse & 0.52 & & & & \\
\hline Ambiguity Neutral & 0.10 & & & & \\
\hline Ambiguity Seeking & 0.38 & & & & \\
\hline \multicolumn{6}{|c|}{ Panel B: Summary Statistics Ambiguity Aversion Measure } \\
\hline & Mean & Std. Dev. & Min & Median & Max \\
\hline Ambiguity Aversion Measure & 0.018 & 0.213 & -0.440 & 0.030 & 0.470 \\
\hline \multicolumn{6}{|c|}{ Panel C: Check Question Responses } \\
\hline & \multicolumn{3}{|c|}{ Not Inconsistent } & & nconsistent \\
\hline Check Question 1 & \multicolumn{3}{|c|}{$69.6 \%$} & & $30.4 \%$ \\
\hline Check Question 2 & \multicolumn{4}{|c|}{$86.0 \%$} & $14.0 \%$ \\
\hline
\end{tabular}




\section{Table 4. Ambiguity aversion and stock market participation}

This table shows results of probit regressions in which the dependent variable equals one if the respondent participates in the stock market. In column (1), the key independent variable is the Ambiguity Aversion measure. In column (2), the key independent variable is an indicator variable equal to one if the respondent is ambiguity averse. In columns (3), the key independent variable is the rank transformation of Ambiguity Aversion. All models include a constant term and controls for age, age-squared divided by a thousand, male, White, Hispanic, married, (ln) number of children (plus one), health, education, employment status, (ln) family income, wealth divided by a hundred thousand, participation in defined contribution or defined benefit plans, financial literacy, trust, risk aversion, question order, check question score, and missing data dummies. The table reports marginal effects. Standard errors are clustered by household and appear in brackets.

\begin{tabular}{|c|c|c|c|}
\hline & (1) & (2) & (3) \\
\hline Ambiguity Aversion & $\begin{array}{l}-0.094 * * \\
{[0.05]}\end{array}$ & & \\
\hline Ambiguity Aversion Dummy & & $\begin{array}{l}-0.039 * * \\
{[0.02]}\end{array}$ & \\
\hline Ambiguity Aversion Rank & & & $\begin{array}{l}-0.073 * * \\
{[0.03]}\end{array}$ \\
\hline Age & $\begin{array}{c}-0.002 \\
{[0.01]}\end{array}$ & $\begin{array}{c}-0.002 \\
{[0.01]}\end{array}$ & $\begin{array}{c}-0.002 \\
{[0.01]}\end{array}$ \\
\hline Age $^{2}$ & $\begin{array}{r}0.143 \\
{[0.24]}\end{array}$ & $\begin{array}{r}0.121 \\
{[0.24]}\end{array}$ & $\begin{array}{r}0.135 \\
{[0.24]}\end{array}$ \\
\hline Male & $\begin{array}{r}0.005 \\
{[0.02]}\end{array}$ & $\begin{array}{r}0.006 \\
{[0.02]}\end{array}$ & $\begin{array}{r}0.006 \\
{[0.02]}\end{array}$ \\
\hline White & $\begin{array}{l}0.045 * \\
{[0.02]}\end{array}$ & $\begin{array}{l}0.047 * \\
{[0.02]}\end{array}$ & $\begin{array}{l}0.045 * \\
{[0.02]}\end{array}$ \\
\hline Hispanic & $\begin{array}{l}-0.092 * * * \\
{[0.03]}\end{array}$ & $\begin{array}{l}-0.092 * * * \\
{[0.03]}\end{array}$ & $\begin{array}{l}-0.092 * * * \\
{[0.03]}\end{array}$ \\
\hline Married & $\begin{array}{l}0.051 * * \\
{[0.02]}\end{array}$ & $\begin{array}{l}0.052 * * \\
{[0.02]}\end{array}$ & $\begin{array}{l}0.051 * * \\
{[0.02]}\end{array}$ \\
\hline Number of Children & $\begin{array}{l}-0.039 * * \\
{[0.02]}\end{array}$ & $\begin{array}{l}-0.039 * * \\
{[0.02]}\end{array}$ & $\begin{array}{l}-0.039 * * \\
{[0.02]}\end{array}$ \\
\hline Health & $\begin{array}{l}0.024 * * \\
{[0.01]}\end{array}$ & $\begin{array}{l}0.025 * * \\
{[0.01]}\end{array}$ & $\begin{array}{l}0.025 * * \\
{[0.01]}\end{array}$ \\
\hline High School & $\begin{array}{l}-0.020 \\
{[0.06]}\end{array}$ & $\begin{array}{l}-0.021 \\
{[0.06]}\end{array}$ & $\begin{array}{l}-0.020 \\
{[0.06]}\end{array}$ \\
\hline College+ & $\begin{array}{r}0.036 \\
{[0.06]}\end{array}$ & $\begin{array}{c}0.034 \\
{[0.06]}\end{array}$ & $\begin{array}{r}0.036 \\
{[0.06]}\end{array}$ \\
\hline Employed & $\begin{array}{r}0.005 \\
{[0.02]}\end{array}$ & $\begin{array}{r}0.005 \\
{[0.02]}\end{array}$ & $\begin{array}{r}0.005 \\
{[0.02]}\end{array}$ \\
\hline Family Income & $\begin{array}{l}0.053 * * * \\
{[0.02]}\end{array}$ & $\begin{array}{l}0.052 * * * \\
{[0.02]}\end{array}$ & $\begin{array}{l}0.053 * * * \\
{[0.02]}\end{array}$ \\
\hline Wealth & $\begin{array}{l}0.035^{* * * *} \\
{[0.01]}\end{array}$ & $\begin{array}{l}0.035 * * * \\
{[0.01]}\end{array}$ & $\begin{array}{l}0.035 * * * \\
{[0.01]}\end{array}$ \\
\hline Defined Contribution & $\begin{array}{l}0.056 * * \\
{[0.02]}\end{array}$ & $\begin{array}{l}0.055 * * \\
{[0.02]}\end{array}$ & $\begin{array}{l}0.055 * * \\
{[0.02]}\end{array}$ \\
\hline Defined Benefit & $\begin{array}{l}-0.054 \\
{[0.02]}\end{array}$ & $\begin{array}{l}-0.052 * * \\
{[0.02]}\end{array}$ & $\begin{array}{l}-0.053 * * \\
{[0.02]}\end{array}$ \\
\hline Financial Literacy & $\begin{array}{l}0.075 * * * \\
{[0.02]}\end{array}$ & $\begin{array}{l}0.076 * * * \\
{[0.02]}\end{array}$ & $\begin{array}{l}0.075 * * * \\
{[0.02]}\end{array}$ \\
\hline Trust & $\begin{array}{c}-0.004 \\
{[0.01]}\end{array}$ & $\begin{array}{l}-0.004 \\
{[0.01]}\end{array}$ & $\begin{array}{c}-0.004 \\
{[0.01]}\end{array}$ \\
\hline Risk Aversion & $\begin{array}{l}0.044 \\
{[0.02]}\end{array}$ & $\begin{array}{l}0.042 * * \\
{[0.02]}\end{array}$ & $\begin{array}{l}0.044 * * \\
{[0.02]}\end{array}$ \\
\hline Question Order & $\begin{array}{r}0.028 \\
{[0.02]}\end{array}$ & $\begin{array}{l}0.029 * \\
{[0.02]}\end{array}$ & $\begin{array}{l}0.030 * \\
{[0.02]}\end{array}$ \\
\hline Errors on Check & $\begin{array}{r}-0.029 \\
{[0.02]}\end{array}$ & $\begin{array}{c}-0.032 \\
{[0.02]}\end{array}$ & $\begin{array}{c}-0.031 \\
{[0.02]}\end{array}$ \\
\hline $\begin{array}{l}\text { Controls and Constant } \\
\mathrm{N}\end{array}$ & $\begin{array}{r}\text { Yes } \\
2,943\end{array}$ & $\begin{array}{r}\text { Yes } \\
2,943\end{array}$ & $\begin{array}{r}\text { Yes } \\
2,943\end{array}$ \\
\hline
\end{tabular}

Notes: * significant at the $10 \%$; ** 5\%; and *** $1 \%$ level. 


\section{Table 5. Ambiguity aversion and portfolio choice: Check questions and financial assets}

This table shows results of probit regressions in which the dependent variable equals one if the respondent participates in the stock market. The main independent variable of interest in Panels A, B, and C are Ambiguity Aversion, Ambiguity Aversion Dummy, and Ambiguity Aversion Rank, respectively. Columns (2) and (4) exclude respondents whose answers to the check question were inconsistent with their earlier choices. Columns (3) and (4) exclude respondents who report financial assets of less than \$500. All models include a constant term and controls for age, age-squared, male, White, Hispanic, married, (ln) number of children (plus one), health, education, employment status, (ln) family income, wealth, participation in defined contribution or defined benefit plans, financial literacy, trust, risk aversion, question order, a check question score equal to one if the subject got either of the check questions wrong: meaning they chose Box $\mathrm{U}$ in the first check question or Box $\mathrm{K}$ in the second check question, and missing data dummies. The table reports marginal effects. Standard errors and are clustered by household and appear in brackets.

\begin{tabular}{|c|c|c|c|c|}
\hline \multicolumn{5}{|l|}{ Panel A } \\
\hline & $(1)$ & $(2)$ & $(3)$ & $(4)$ \\
\hline \multirow[t]{2}{*}{ Ambiguity Aversion } & $-0.094 * *$ & $-0.121 *$ & $-0.167 * *$ & $-0.225 * *$ \\
\hline & {$[0.05]$} & {$[0.07]$} & {$[0.07]$} & {$[0.10]$} \\
\hline Consistent Responses Only & No & Yes & No & Yes \\
\hline Financial Assets $\geq \$ 500$ & No & No & Yes & Yes \\
\hline Controls and Constant & Yes & Yes & Yes & Yes \\
\hline $\mathrm{N}$ & 2,943 & 1,746 & 1,881 & 1,199 \\
\hline \multicolumn{5}{|l|}{ Panel B } \\
\hline & $(1)$ & $(2)$ & $(3)$ & $(4)$ \\
\hline \multirow[t]{2}{*}{ Ambiguity Aversion Dummy } & $-0.039 * *$ & -0.031 & $-0.072 * * *$ & $-0.058 *$ \\
\hline & {$[0.02]$} & {$[0.02]$} & {$[0.03]$} & {$[0.03]$} \\
\hline Consistent Responses Only & No & Yes & No & Yes \\
\hline Financial Assets $\geq \$ 500$ & No & No & Yes & Yes \\
\hline Controls and Constant & Yes & Yes & Yes & Yes \\
\hline $\mathrm{N}$ & 2,943 & 1,746 & 1,881 & 1,199 \\
\hline \multicolumn{5}{|l|}{ Panel C } \\
\hline & $(1)$ & $(2)$ & (3) & $(4)$ \\
\hline \multirow[t]{2}{*}{ Ambiguity Aversion Rank } & $-0.073 * *$ & $-0.080 *$ & $-0.137 * * *$ & $-0.149 * *$ \\
\hline & {$[0.03]$} & {$[0.05]$} & {$[0.05]$} & {$[0.07]$} \\
\hline Consistent Responses Only & No & Yes & No & Yes \\
\hline Financial Assets $\geq \$ 500$ & No & No & Yes & Yes \\
\hline Controls and Constant & Yes & Yes & Yes & Yes \\
\hline $\mathrm{N}$ & 2,943 & 1,746 & 1,881 & 1,199 \\
\hline
\end{tabular}

Notes: * significant at the $10 \%$; ** 5\%; and *** $1 \%$ level. 


\section{Table 6. Ambiguity aversion and the fraction of financial assets allocated to stocks}

This table shows results for Tobit regression for which the dependent variable refers to the fraction of financial assets allocated to equities. Column (2) excludes respondents who do not participate in the stock market. All models include a constant term and controls for age, age-squared, male, White, Hispanic, married, (ln) number of children (plus one), health, education, employment status, (ln) family income, wealth, participation in defined contribution or defined benefit plans, financial literacy, trust, risk aversion, question order, check question score, and missing data dummies. Standard errors are clustered by household and appear in brackets.

\begin{tabular}{lcc}
\hline & $(1)$ & $(2)$ \\
\hline Ambiguity Aversion & $-0.379 * *$ & $-0.193^{*}$ \\
& {$[0.15]$} & {$[0.10]$} \\
Equity Ownership $>0$ Only & No & Yes \\
Controls and Constant & Yes & Yes \\
$\mathrm{N}$ & 2,943 & 731 \\
\hline
\end{tabular}

Notes: * significant at the $10 \%$;* $5 \%$; and *** $1 \%$ level. 


\section{Table 7. Ambiguity aversion: Foreign stocks and own-company stock ownership}

This table shows results for probit regressions in which the dependent variable equals one if the respondent holds foreign stock or own-company stock. Columns (1) and (2) show probit regression results for foreign stock ownership. Columns (3) and (4) show probit regression results for own-company stock ownership. Columns (2) and (4) exclude respondents who do not participate in the stock market. Columns (3) and (4) exclude respondents who are not currently employed. All models include a constant term and controls for age, age-squared, male, White, Hispanic, married, (ln) number of children (plus one), health, education, employment status, (ln) family income, wealth, participation in defined contribution or defined benefit plans, financial literacy, trust, risk aversion, question order, check question score, and missing data dummies. The table reports marginal effects. Standard errors are clustered by household and appear in brackets.

\begin{tabular}{lcccc}
\hline & \multicolumn{2}{l}{ Foreign Stock Ownership } & \multicolumn{2}{c}{ Own-Company Stock } \\
\cline { 2 - 5 } & & $(2)$ & $(3)$ & Ownership \\
& $(1)$ & $-0.380^{* *}$ & $0.069^{*}$ & $0.557^{* *}$ \\
\hline Ambiguity Aversion & $-0.126^{* *}$ & {$[0.15]$} & {$[0.04]$} & {$[0.22]$} \\
& {$[0.06]$} & Yes & No & Yes \\
Equity Ownership>0 Only & No & Yes & Yes & Yes \\
Controls and Constant & Yes & 258 & 664 & 155 \\
$\mathrm{~N}$ & 779 & & & \\
\hline
\end{tabular}

Notes: * significant at the $10 \%$; ** 5\%; and *** $1 \%$ level. 


\section{Table 8. Ambiguity aversion and stock market competence}

This table shows results for probit regressions in which the dependent variable is equals one if the respondent participates in the stock market. Column (1) includes no interaction term between stock market competence and Ambiguity Aversion (AA). Column (2) includes interaction terms between the level of self-assessed stock market knowledge and Ambiguity Aversion and column (3) includes interaction terms between the level of financial literacy and Ambiguity Aversion (AA). Respondents have low literacy if their answer to one or more of the three financial literacy questions is wrong. Respondents have low knowledge if they answered 'very low' to the question: "How would you rate your knowledge about the stock market?" All models include a constant term and controls for age, age-squared, male, White, Hispanic, married, (ln) number of children (plus one), health, education, employment status, (ln) family income, wealth, participation in defined contribution or defined benefit plans, financial literacy, trust, risk aversion, question order, check question score, and missing data dummies. The table reports marginal effects. Standard errors are clustered by household and appear in brackets.

\begin{tabular}{lccc}
\hline & $\begin{array}{c}\text { So Interaction } \\
(1)\end{array}$ & $\begin{array}{c}\text { Competence } \\
(2)\end{array}$ & $\begin{array}{c}\text { Financial Literacy } \\
(3)\end{array}$ \\
\hline Ambiguity Aversion & $-0.094^{* *}$ & & \\
& {$[0.05]$} & & $-0.157 * *$ \\
AA: Low Stock Market Competence & & $-0.219 * * *$ & {$[0.07]$} \\
& & {$[0.08]$} & -0.041 \\
AA: High Stock Market Competence & & -0.055 & {$[0.06]$} \\
& $0.075 * * *$ & {$[0.05]$} & $0.122 * * *$ \\
Stock Market Competence & {$[0.02]$} & $0.182 * * *$ & {$[0.02]$} \\
& Yes & {$[0.02]$} & Yes \\
Controls and Constant & 2,943 & 2,943 & 2,943 \\
\hline
\end{tabular}

Notes: * significant at the $10 \%$; ** 5\%; and *** $1 \%$ level. 


\section{Table 9. Ambiguity aversion and under-diversification}

This table shows results for regressions in which the dependent variables indicate ownership of individual stocks. Columns (1), (2), and (3) show probit regression results in which the dependent variable equals one if the respondent reports ownership of individual stocks. Columns (4), (5), and (6) show Tobit regression results in which the dependent variable is the fraction of equity invested in individual stocks. Columns (1) and (4) include no interaction term between stock market competence and Ambiguity Aversion (AA). Column (2) and (5) include interaction terms between the level of self-assessed stock market knowledge and Ambiguity Aversion and column (3) and (6) include interaction terms between the level of financial literacy and Ambiguity Aversion. Respondents have low literacy if their answer to one or more of the three financial literacy questions is wrong. Respondents have low knowledge if they answered 'very low' to the question: "How would you rate your knowledge about the stock market?" All models include a constant term and controls for age, age-squared, male, White, Hispanic, married, (ln) number of children (plus one), health, education, employment status, (ln) family income, wealth, participation in defined contribution or defined benefit plans, financial literacy, trust, risk aversion, question order, check question score, and missing data dummies. The table reports marginal effects. Standard errors are clustered by household and appear in brackets.

\begin{tabular}{|c|c|c|c|c|c|c|}
\hline & \multicolumn{3}{|c|}{ Individual Stocks Ownership } & \multicolumn{3}{|c|}{ Fraction of Equity in Individual Stocks } \\
\hline & $\begin{array}{c}\text { No Interaction } \\
\text { (1) }\end{array}$ & $\begin{array}{c}\text { Stock Market } \\
\text { Competence } \\
\text { (2) }\end{array}$ & $\begin{array}{c}\text { Financial } \\
\text { Literacy } \\
\text { (3) }\end{array}$ & $\begin{array}{c}\text { No Interaction } \\
\text { (4) }\end{array}$ & $\begin{array}{l}\text { Stock Market } \\
\text { Competence } \\
\text { (5) }\end{array}$ & $\begin{array}{c}\text { Financial } \\
\text { Literacy } \\
(6)\end{array}$ \\
\hline Ambiguity Aversion & $\begin{array}{l}-0.413 * * * \\
{[0.11]}\end{array}$ & & & $\begin{array}{l}-0.548 * * * \\
{[0.06]}\end{array}$ & & \\
\hline AA: Low Stock Market Competence & & $\begin{array}{r}-0.080 \\
{[0.26]}\end{array}$ & $\begin{array}{r}-0.212 \\
{[0.19]}\end{array}$ & & $\begin{array}{l}2.189 * * * \\
{[0.23]}\end{array}$ & $\begin{array}{l}0.501 * * * \\
{[0.08]}\end{array}$ \\
\hline AA: High Stock Market Competence & & $\begin{array}{l}-0.456 * * * \\
{[0.12]}\end{array}$ & $\begin{array}{l}-0.479 * * * \\
{[0.13]}\end{array}$ & & $\begin{array}{l}-0.639 * * * \\
{[0.06]}\end{array}$ & $\begin{array}{l}-0.815 * * * \\
{[0.07]}\end{array}$ \\
\hline Stock Market Competence & $\begin{array}{l}-0.013 \\
{[0.04]}\end{array}$ & $\begin{array}{r}0.071 \\
{[0.07]}\end{array}$ & $\begin{array}{l}-0.032 \\
{[0.05]}\end{array}$ & $\begin{array}{l}0.057 * * \\
{[0.03]}\end{array}$ & $\begin{array}{r}0.008 \\
{[0.08]}\end{array}$ & $\begin{array}{r}0.069 \\
{[0.07]}\end{array}$ \\
\hline $\begin{array}{l}\text { Controls and Constant } \\
\mathrm{N}\end{array}$ & $\begin{array}{l}\text { Yes } \\
701\end{array}$ & $\begin{array}{l}\text { Yes } \\
701\end{array}$ & $\begin{array}{l}\text { Yes } \\
701\end{array}$ & $\begin{array}{l}\text { Yes } \\
319\end{array}$ & $\begin{array}{l}\text { Yes } \\
319\end{array}$ & $\begin{array}{l}\text { Yes } \\
319\end{array}$ \\
\hline
\end{tabular}




\section{Table 10. Ambiguity aversion and reactions to the financial crisis}

This table shows results for a probit regression in which the dependent variable equals one if the respondent actively sold equities during the financial crisis. The sample includes only those who owned equities prior to the crisis. The model includes a constant term and controls for age, age-squared, male, White, Hispanic, married, ln number of children, health, education, employment status, ln family income, wealth, participation in defined contribution or defined benefit plans, financial literacy, trust, risk aversion, question order, check question score, and missing data dummies. The table reports marginal effects. Standard errors are clustered by household and appear in brackets.

\begin{tabular}{lc}
\hline & $(1)$ \\
\hline Ambiguity Aversion & $0.215 * * *$ \\
& {$[0.06]$} \\
Controls and Constant & Yes \\
$\mathrm{N}$ & 524 \\
\hline Notes: * significant at the $10 \% ; * * 5 \% ;$ and & *** $1 \%$ level.
\end{tabular}




\title{
Online Appendixes for “Ambiguity Aversion and Household Portfolio Choice Puzzles: Empirical Evidence”
}

\author{
Stephen G. Dimmock, Roy Kouwenberg, Olivia Mitchell, and Kim Peijnenburg
}




\section{Online Appendix A: Detailed description of the procedure for eliciting ambiguity aversion}

This Appendix describes our procedure for measuring ambiguity aversion in the ALP survey. The module starts with an introduction screen explaining the basic setup of the questions: see Figure A-1. The introduction screen also explains that, after completing the survey, one of the respondent's choices in the set of thee ambiguity gain questions will be selected randomly by the computer and played for a real reward of $\$ 15$.

Figure A-1 here

In the next screen, shown in Figure 1 of the paper, the respondent is offered a choice between Box K, containing 50 purple and 50 orange balls, and Box U, containing an unknown mix of 100 purple and orange balls. Three response options are available: Box K, Box U, and Indifferent. If the respondent clicks the "Next" button before answering the question, the respondent is shown a message that all responses are important and is asked to answer the question again.

If the respondent selects "Indifferent", the matching probability $(q)$ is exactly $50 \%$ and the procedure continues with the second ambiguity question, described further on. If the respondent chooses Box $\mathrm{K}$, she is ambiguity averse and we know that the matching probability is less than $50 \%(0 \% \leq q<50 \%)$. In the following round, the number of winning balls in Box $\mathrm{K}$ is reduced to 25: see Figure A-2. If the respondent selected Box $U$ in the first round instead, she is ambiguity seeking $(0 \geq q>50 \%)$ and in the second round the number of winning balls in Box K is increased to 75 .

Figure A-2 here

The bisection algorithm continues this way for an additional three rounds (four rounds in total). In every round of the bisection algorithm, the difference between the lower bound and the upper round on the matching probability is reduced by half. When the option "Indifferent" is chosen, the algorithm stops earlier, as then the upper and lower bounds are equal. After a maximum of four rounds, we take the average of the lower and upper bound, the midpoint, as the estimate of the matching probability $(q)$. Table A-1 shows all 27 possible outcome paths of the bisection algorithm, with corresponding matching probabilities. For two paths representing extremely ambiguity seeking attitudes ( $q>75 \%$, paths UUK and UUU) we require less measurement accuracy and the algorithm stops after three rounds to save time.

\section{Table A-1 here}

\section{Check questions to test for consistency of subjects' answers}

To test for the consistency of the answers we included two check questions. Using the answers to the ambiguity question (two ball colors, 50\% ambiguity-neutral) we calculated the matching probability for each subject $(q)$. To generate Check Question 1, we lowered the known probability of winning for Box K to each subjects' matching probability minus 10 percentage points $(q-0.1)$. In that case, the subject should choose the ambiguous Box U. To generate Check Question 2, we increased the known probability of winning of Box K to the matching probability plus 10 percentage points $(q+0.1)$. In that case, the subject should choose the unambiguous Box K. Note that the maximum known probability is set at 99 and the minimum is set at 1 , to avoid certainty. 


\section{Table A-1: Responses and matching probabilities for the ambiguity question}

This table shows the possible outcomes in the four rounds of the ambiguity question, with two ball colors and initial 50\% chance of winning for Box K. Panel A shows the transitions of the bisection algorithm, starting at Q1a, offering a choice between Box K with known winning probability $\mathrm{p}=50 \%$ and ambiguous Box U. If the respondent chooses Box $\mathrm{K}$, then next question round is Q1b (with $\mathrm{p}=75 \%$ ), while round Q1i (with $\mathrm{p}=25 \%$ ) follows after response Box U. After a choice of Indifferent, the algorithm always stops. Panel B shows the list of 27 possible response paths in the four question rounds. The letter combination in the column 'Response' summarizes one potential choices path, with $\mathrm{K}$ and $\mathrm{U}$ denoting the boxes, and I for Indifferent. The column q shows the corresponding matching probability, which is exact for paths ending with I and the average of the lower and upper bound for all other paths. For example, "KUUK" means the respondent chose Box K, followed by U twice, and then K. For this path the bounds on the matching probability are $38 \%$ and $44 \%$, with midpoint $q=41 \%$. The path "I" represents an Indifferent choice in the first round $(q=50 \%)$. For paths UUK, UUI and UUU, extreme ambiguity seeking, we require less accuracy and the algorithm stops after three rounds to save time.

\begin{tabular}{lccccc}
\hline \multicolumn{6}{l}{ Panel A: Probability of Winning for Box K and Transitions } \\
\hline Question & Purple balls & Orange balls & \multicolumn{4}{l}{ Next round after response } \\
\cline { 4 - 6 } Round & in Box K (p) & $(100-\mathrm{p})$ & Box K & Box U & Indifferent \\
\hline Q1a & 50 & 50 & Q1b & Q1i & stop \\
Q1b & 25 & 75 & Q1c & Q1f & stop \\
Q1c & 12 & 88 & Q1d & Q1e & stop \\
Q1d & 6 & 94 & stop & stop & stop \\
Q1e & 18 & 82 & stop & stop & stop \\
Q1f & 38 & 62 & Q1g & Q1h & stop \\
Q1g & 32 & 68 & stop & stop & stop \\
Q1h & 44 & 56 & stop & stop & stop \\
Q1i & 75 & 25 & Q1j & Q1m & stop \\
Q1j & 62 & 38 & Q1k & Q1l & stop \\
Q1k & 56 & 44 & stop & stop & stop \\
Q1l & 68 & 32 & stop & stop & stop \\
Q1m & 88 & 12 & stop & stop & stop \\
\hline
\end{tabular}

\begin{tabular}{lclclc}
\hline \multicolumn{2}{l}{ Panel B: Outcome Paths } & & & \\
Response & $q$ & Response & $q$ & Response & $q$ \\
\hline KKKK & 3 & KUKI & 32 & UKKU & 59 \\
KKKI & 6 & KUKU & 35 & UKI & 62 \\
KKKU & 9 & KUI & 38 & UKUK & 65 \\
KKI & 12 & KUUK & 41 & UKUI & 68 \\
KKUK & 15 & KUUI & 44 & UKUU & 71.5 \\
KKUI & 18 & KUUU & 47 & UI & 75 \\
KKUU & 21.5 & I & 50 & UUK & 81.5 \\
KI & 25 & UKKK & 53 & UUI & 88 \\
KUKK & 28.5 & UKKI & 56 & UUU & 94 \\
\hline
\end{tabular}


Figure A-1: Screen shot: Text introducing the ambiguity questions

You can win additional money on top of your regular payment for answering the survey, by answering the next questions.

You will be asked to choose between two boxes, Box K and Box U. Each box contains 100 balls of different colors. After you choose a box, one ball is drawn out of that box. If the ball is the right color, you could win $\$ 15$. There are no right or wrong answers for these questions. If you feel both boxes are equally attractive, please choose Indifferent.

After completing the survey, one of the questions you answered will be selected randomly by the computer and played for real money. Your winnings will be based on the choices you made.

Next $>$

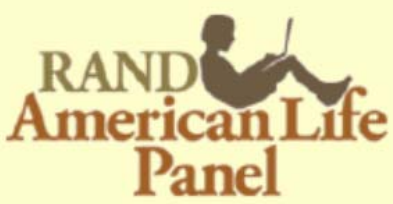




\section{Figure A-2: Screen shot: Second round of the ambiguity question after Choice $\mathrm{K}$}

This Figure shows a screen shot from our ALP module, representing the second round of the ambiguity elicitation question. Box K now has a 25\% known probability of winning; Box U has an unknown mix of balls with two different colors. After answering this question, respondents are led to a new round of the question. Selecting the "Indifferent" button finishes the question. If the respondent selects "Box K", he gets a new question with a lower probability of winning in Box K (fewer purple balls), while if he selects "Box U", the next question has a higher winning probability of winning in Box K (more purple balls).

In the next question you can choose either Box K or Box U. Both hold 100 balls which can either be purple or orange.

For Box K, the exact mix of purple balls and orange balls is given below.

Box $\mathrm{U}$ also holds purple and orange balls, but the mix is unknown.

In other words, both boxes hold 100 balls with two different colors (purple and orange). The mix of purple and orange balls is known for Box $\mathrm{K}$ and unknown for Box U.

One ball will be drawn at random from the box you choose. You will win $\$ 15$ if a purple ball is drawn.

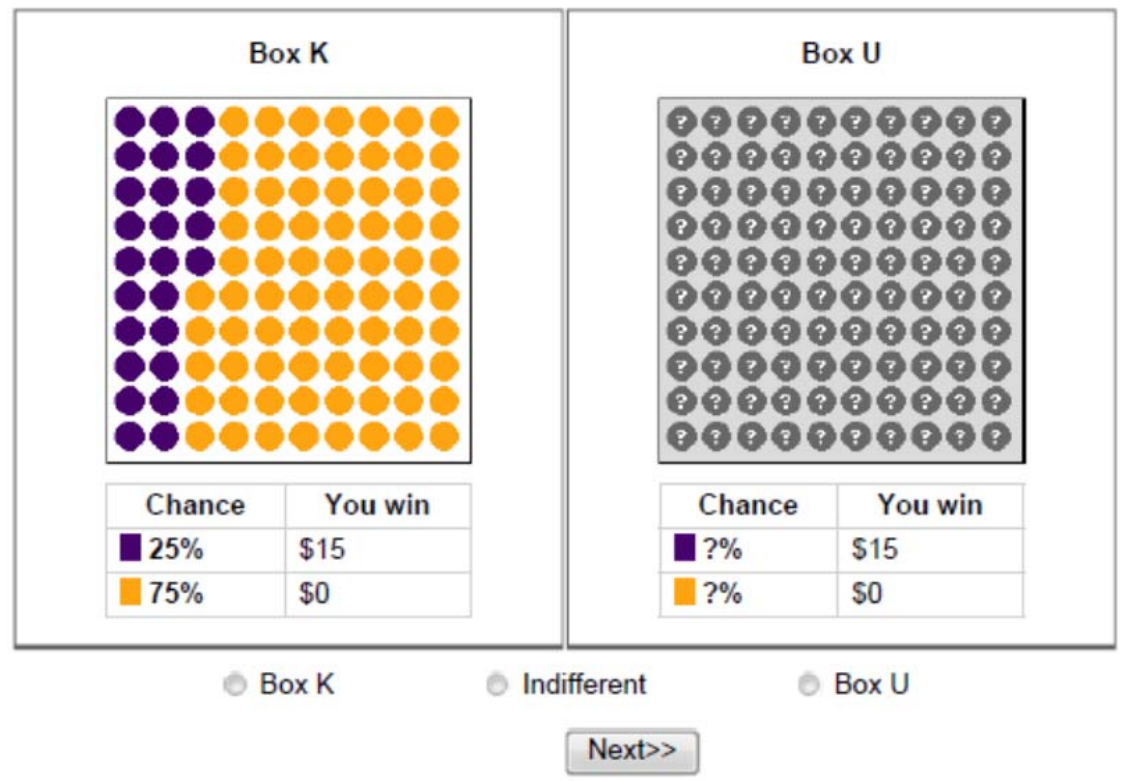




\section{Online Appendix B: The ALP survey and main control variables}

\section{Description of the American Life Panel}

The American Life Panel (ALP) is an Internet panel of U.S. respondents age 18+; respondents were recruited in one of four ways (https://mmicdata.rand.org/alp/). Most were recruited from respondents to the Monthly Survey (MS) of the University of Michigan's Survey Research Center (SRC). The MS is the leading consumer sentiment survey that incorporates the longstanding Survey of Consumer Attitudes and produces, among others, the widely used Index of Consumer Expectations. Each month, the MS interviews approximately 500 households, of which 300 households are a random-digit-dial (RDD) sample and 200 are re-interviewed from the RDD sample surveyed six months previously. Until August 2008, SRC screened MS respondents by asking them if they would be willing to participate in a long-term research project (with approximate response categories "no, certainly not," "probably not," "maybe," "probably," “yes, definitely”). If the response category is not "no, certainly not," respondents were told that the University of Michigan is undertaking a joint project with RAND. They were asked if they would object to SRC sharing their information about them with RAND so that they could be contacted later and asked if they would be willing to actually participate in an Internet survey. Respondents who do not have Internet were told that RAND will provide them with free Internet. Many MS-respondents are interviewed twice. At the end of the second interview, an attempt was made to convert respondents who refused in the first round. This attempt includes the mention of the fact that participation in follow-up research carries a reward of $\$ 20$ for each half-hour interview.

Respondents from the Michigan monthly survey without Internet were provided with socalled WebTVs (http://www.webtv.com/pc/), which allows them to access the Internet using their television and a telephone line. The technology allows respondents who lacked Internet access to participate in the panel and furthermore use the WebTVs for browsing the Internet or email. The ALP has also recruited respondents through a snowball sample (respondents suggesting friends or acquaintances who might also want to participate), but we do not use any respondents recruited through the snowball sample in our paper. A new group of respondents (approximately 500) was recruited after participating in the National Survey Project at Stanford University. This sample was recruited in person, and at the end of their one-year participation, they were asked whether they were interested in joining the RAND American Life Panel. Most of these respondents were given a laptop and broadband Internet access.

\section{Financial Literacy}

The financial literacy questions we posed in the ALP module have been used in two dozen countries and comparable results obtained (Lusardi and Mitchell, 2011):

Suppose you had $\$ 100$ in a savings account and the interest rate was $2 \%$ per year. After 5 years, how much do you think you would have in the account if you left the money to grow?

1) More than $\$ 102$

2) Exactly $\$ 102$

3) Less than $\$ 102$

4) Don't know 
Imagine that the interest rate on your savings account was $1 \%$ per year and inflation was $2 \%$ per year. After 1 year, would you be able to buy more than, exactly the same as, or less than today with the money in this account?

1) More than today

2) Exactly the same as today

3) Less than today

4) Don't know

Please tell us whether this statement is true or false. Buying a single company stock usually provides a safer return than a stock mutual fund.

1) True

2) False

3) Don't know

\section{Trust}

The trust question we use was: "Generally speaking, would you say that most people can be trusted, or that you can't be too careful in dealing with people? Please indicate on a score of 0 to 5.”). For the answers, we employ a Likert scale ranging from 0 to 5, with 0 indicating strong agreement and 5 indicating strong disagreement.

\section{Risk Aversion}

To measure risk aversion, we build on Tanaka, Camerer, and Nguyen (2010), who ask respondents to select from a list consisting of 14 tradeoffs between two gambles. We modify their approach and use a sequence of binary choices similar to the method for eliciting ambiguity aversion described previously, as illustrated in Figure 2. If a respondent selects the certain outcome, he is then shown another choice with a higher expected value for the risky outcome. If he selects the risky outcome, he is then shown another choice with a lower expected value for the risky outcome. This process is repeated until risk aversion is sufficiently well-approximated. We use the responses to estimate each respondent's risk aversion, measured as the coefficient of relative risk aversion assuming a power utility function. ${ }^{36}$

\footnotetext{
${ }^{36}$ As in Tanaka, Camerer, and Nguyen (2010), the payoffs of the gambles are not integrated with total wealth in the utility function, and the power coefficient is limited to the range from 0 to 1.5 . Risk aversion is defined as: 1 - power function coefficient, and varies from -0.5 (risk seeking) to +1 (strongest level of risk aversion). A value of zero implies risk neutrality.
} 


\section{Online Appendix C: Additional results}

To further explore ambiguity attitudes across demographic and economic characteristics, Column (1) of Table C-1 shows the results from regressing the ambiguity aversion measures on key control variables for the entire sample. Naturally the regressions do not imply any causal relation; rather, multiple regression is a convenient tool to concisely summarize the correlation structure of the data. In columns (2-4), we restrict the sample to certain groups of interest. Column (2) includes only respondents whose check question answers did not contradict their earlier choice. Column (3) includes only respondents with a college degree. Column (4) includes only respondents with at least $\$ 500$ in financial assets. The results are similar across columns.

\section{Table C-1 here}

The results show that men are more ambiguity averse than women. College-educated respondents are more ambiguity averse than the less educated, suggesting that ambiguity aversion measures preferences rather than cognitive errors (i.e., such as cognitive errors due to using simplifying heuristics for complicated problems). There is also a positive relation between ambiguity aversion and risk aversion, consistent with Bossaerts, Ghirardato, Guarnaschelli, and Zame (2010).

We also find that the survey question order matters: that is, measured ambiguity aversion proves to be higher when the risk aversion questions are presented before the ambiguity aversion questions. Such an order effect is consistent with the "comparative ignorance" hypothesis of Fox and Tversky (1995), which posits that ambiguity aversion is magnified by comparisons to less ambiguous events (in this case, the preceding risk questions with known probabilities). Because of this issue, we randomized the order of the risk and ambiguity questions in the ALP survey, and we also include an indicator variable for question order in the empirical analyses.

Perhaps the most striking aspect of Table C-1 is that the adjusted R-square values are consistently low; the controls explain less than eight percent of the variance in ambiguity aversion. Even in column (2), in which the dependent variable likely contains less measurement error, the adjusted R-square is low. This suggests that our measure of ambiguity aversion captures new information about preferences which is not subsumed by standard demographic and economic controls. 


\section{Table C-1: Relation of ambiguity aversion with economic and demographic variables}

This table shows the results of OLS regressions in which the dependent variable is Ambiguity Aversion defined in Table $3(50 \%-q)$. The independent variables are defined in Table 1 . Constant terms and retirement plan type indicator variables are included in the regressions, but not displayed in the interest of brevity. The coefficients are multiplied by 100 to enhance readability. Column (3) excludes respondents who gave inconsistent responses to either of the two check questions. Column (2) excludes respondents without a college degree. Column (4) excludes respondents with less than $\$ 500$ in financial wealth. Standard errors are clustered by household and appear in brackets.

\begin{tabular}{|c|c|c|c|c|}
\hline & Full Sample & Not Inconsistent & College Educated & Fin. Wealth $\geq \$ 500$ \\
\hline & $(1)$ & $(2)$ & (3) & $(4)$ \\
\hline \multirow[t]{2}{*}{ Age } & $-0.504 *$ & -0.436 & -0.355 & $-0.963 * *$ \\
\hline & {$[0.30]$} & {$[0.34]$} & {$[0.34]$} & {$[0.40]$} \\
\hline \multirow{2}{*}{$\mathrm{Age}^{2}$} & 0.004 & 0.004 & 0.002 & $0.010 * *$ \\
\hline & {$[0.00]$} & {$[0.00]$} & {$[0.00]$} & {$[0.00]$} \\
\hline \multirow[t]{2}{*}{ Male } & $3.490 * * *$ & $3.811 * * *$ & 1.125 & $2.859 * *$ \\
\hline & [1.01] & [1.05] & [1.18] & [1.13] \\
\hline \multirow{2}{*}{ White } & $-3.195 * *$ & -1.155 & -2.877 & $-4.264 * *$ \\
\hline & [1.43] & [1.42] & [1.75] & [1.98] \\
\hline \multirow[t]{2}{*}{ Hispanic } & 0.661 & 1.450 & $5.010 * *$ & -0.443 \\
\hline & [1.53] & [1.62] & {$[2.46]$} & [1.97] \\
\hline \multirow[t]{2}{*}{ Married } & 0.858 & -0.059 & 0.665 & 1.222 \\
\hline & [1.31] & [1.46] & [1.48] & [1.55] \\
\hline \multirow{2}{*}{ Number of Children } & 0.322 & 0.383 & -0.224 & 0.411 \\
\hline & [0.92] & {$[1.02]$} & {$[1.26]$} & [1.09] \\
\hline \multirow[t]{2}{*}{ Health } & 0.141 & -0.670 & 0.555 & 0.242 \\
\hline & [0.63] & {$[0.74]$} & [0.73] & [0.82] \\
\hline \multirow[t]{2}{*}{ High School } & 2.042 & -2.612 & & 3.237 \\
\hline & [2.17] & {$[2.45]$} & & {$[4.20]$} \\
\hline \multirow[t]{2}{*}{ College } & $4.455 *$ & 0.590 & & 5.541 \\
\hline & {$[2.28]$} & {$[2.58]$} & & [4.12] \\
\hline \multirow[t]{2}{*}{ Employed } & -0.146 & -0.352 & $2.620 *$ & 0.401 \\
\hline & [1.17] & [1.18] & [1.43] & [1.30] \\
\hline \multirow[t]{2}{*}{ Family Income } & 1.004 & 1.235 & 0.232 & 0.977 \\
\hline & {$[0.74]$} & {$[0.85]$} & {$[0.97]$} & {$[1.02]$} \\
\hline \multirow[t]{2}{*}{ Wealth } & -0.367 & -1.008 & $1.736 * *$ & -0.619 \\
\hline & {$[0.81]$} & {$[0.91]$} & {$[0.80]$} & {$[0.87]$} \\
\hline \multirow[t]{2}{*}{ DC pension plan } & -0.185 & -0.565 & 0.831 & 0.837 \\
\hline & [1.27] & [1.32] & [1.45] & [1.40] \\
\hline \multirow[t]{2}{*}{ DB pension plan } & -1.608 & -2.150 & $-5.096 * * *$ & -1.942 \\
\hline & [1.56] & [1.74] & [1.90] & [1.67] \\
\hline \multirow[t]{2}{*}{ Financial Literacy } & -0.228 & 0.326 & $1.613 *$ & -0.016 \\
\hline & {$[0.76]$} & {$[0.80]$} & {$[0.98]$} & [0.97] \\
\hline \multirow[t]{2}{*}{ Trust } & 0.374 & 0.284 & 0.605 & $0.890 *$ \\
\hline & {$[0.40]$} & {$[0.39]$} & {$[0.47]$} & {$[0.46]$} \\
\hline \multirow[t]{2}{*}{ Risk Aversion } & $8.521 * * *$ & $5.757 * * *$ & $6.951 * * *$ & $6.302 * * *$ \\
\hline & {$[1.24]$} & {$[1.24]$} & {$[1.49]$} & {$[1.44]$} \\
\hline \multirow[t]{2}{*}{ Question Order } & $6.708 * * *$ & $4.770 * * *$ & $6.883 * * *$ & $7.488 * * *$ \\
\hline & [0.99] & {$[1.04]$} & [1.19] & {$[1.16]$} \\
\hline \multirow[t]{2}{*}{ Errors on Check } & $-5.969 * * *$ & & $-5.949 * * *$ & $-5.938 * * *$ \\
\hline & [1.09] & & {$[1.40]$} & {$[1.28]$} \\
\hline Adjusted-R ${ }^{2}$ & 0.093 & 0.052 & 0.105 & 0.100 \\
\hline $\mathrm{N}$ & 2,972 & 1,766 & 1,182 & 1,884 \\
\hline
\end{tabular}

Notes: * significant at the $10 \%$; ** 5\%; and *** $1 \%$ level. 


\section{Appendix References}

Bossaerts, P., P. Ghirardato, S. Guarnaschelli, and W. Zame. 2010. Ambiguity in Asset Markets: Theory and Experiment. Review of Financial Studies 23, 1325-1359.

Fox, C.R., and A. Tversky. 1998. A Belief Based Account of Decision under Uncertainty. Management Science 44, 879-895.

Lusardi, A., and O.S. Mitchell. 2011. Financial Literacy around the World: An Overview. Journal of Pension Economics and Finance 10, 497-508.

Tanaka, T., C.F. Camerer, and Q. Nguyen. 2010. Risk and Time Preferences: Linking Experimental and Household Survey Data from Vietnam. American Economic Review 100, 557-571. 